\title{
Endoscopic management of common bile duct stones: European Society of Gastrointestinal Endoscopy (ESGE) guideline
}

Authors

Gianpiero Manes ${ }^{1}$, Gregorios Paspatis ${ }^{2}$, Lars Aabakken ${ }^{3}$, Andrea Anderloni ${ }^{4}$, Marianna Arvanitakis ${ }^{5}$, Philippe Ah-Soune $^{6}$, Marc Barthet ${ }^{7}$, Dirk Domagk ${ }^{8}$, Jean-Marc Dumonceau ${ }^{9}$, Jean-Francois Gigot ${ }^{10}$, Istvan Hritz ${ }^{11}$, George Karamanolis ${ }^{12}$, Andrea Laghi ${ }^{13}$, Alberto Mariani ${ }^{14}$, Konstantina Paraskeva ${ }^{15}$, Jürgen Pohl ${ }^{16}$, Thierry Ponchon ${ }^{17}$, Fredrik Swahn ${ }^{18}$, Rinze W. F. ter Steege ${ }^{19}$, Andrea Tringali ${ }^{20}$, Antonios Vezakis ${ }^{21}$, Earl J. Williams ${ }^{22}$, Jeanin E. van Hooft ${ }^{23}$

\section{Institutions}

1 Department of Gastroenterology, ASST Rhodense, Rho and Garbagnate M.se Hospitals, Milan, Italy

2 Gastroenterology Department, Benizelion General Hospital, Heraklion, Crete, Greece

3 GI Endoscopy, Rikshospitalet University Hospital, Hospital and Faculty of Medicine, University of Oslo, Oslo, Norway

4 Digestive Endoscopy Unit, Division of Gastroenterology, Humanitas Research Hospital, Rozzano, Milan, Italy

5 Department of Gastroenterology, Hepatology and Digestive Oncology, Erasme University Hospital Université Libre de Bruxelles, Brussels, Belgium

6 Service d'Hépato-Gastroentérologie, Hôpital SaintMusse, Toulon, France

7 Service d'Hépato-gastroentérologie, Hôpital Nord, Marseille, France

8 Department of Medicine B, University of Münster, Münster, Germany

9 Gedyt Endoscopy Center, Buenos Aires, Argentina

10 Department of Abdominal Surgery and Transplantation, Cliniques Universitaires Saint-Luc, Université Catholique de Louvain, Brussels, Belgium

11 Semmelweis University, 1st Department of Surgery, Endoscopy Unit, Budapest, Hungary

12 Academic Department of Gastroenterology, Laiko General Hospital, Medical School, National and Kapodistrian University of Athens, Athens, Greece

13 Pathological Sciences, Sapienza University, Rome, Italy

14 Pancreato-Biliary Endoscopy and Endosonography Division, Pancreas Translational \& Clinical Research Center, Vita-Salute San Raffaele University, IRCCS San Raffaele Scientific Institute, Milan, Italy

15 Gastroenterology Unit, Konstantopoulio General Hospital, Athens, Greece

16 Department of Gastroenterology and Interventional Endoscopy, Klinikum Friedrichshain, Berlin, Germany

17 Department of Digestive Diseases, Hôpital Edouard Herriot, Lyon, France
18 Center for Digestive Diseases, Karolinska University Hospital and Division of Surgery, CLINTEC, Karolinska Institute, Stockholm, Sweden

19 Department of Gastroenterology and Hepatology, University of Groningen, University Medical Center Groningen, Groningen, The Netherlands

20 Digestive Endoscopy Unit, Catholic University, Rome, Italy

21 Gastroenterology Unit, 2 Department of Surgery, School of Medicine, National and Kapodistrian University of Athens, Athens, Greece

22 Department of Gastroenterology, Royal Bournemouth Hospital, Bournemouth, UK

23 Department of Gastroenterology and Hepatology, Amsterdam University Medical Center, University of Amsterdam, Amsterdam, The Netherlands

Bibliography

DOI https://doi.org/10.1055/a-0862-0346

Published online: 3.4.2019 | Endoscopy 2019; 51: 472-491

(c) Georg Thieme Verlag KG Stuttgart · New York

ISSN 0013-726X

Corresponding author

Gianpiero Manes, MD, Department of Gastroenterology, ASST Rhodense, Rho and Garbagnate M.se Hospitals, Viale Forlanini 95, 20024 Garbagnate M.se, Milano, Italy gimanes@tin.it

$\bigoplus$ Appendix 1s, Tables 1s-14s Online content viewable at: https://doi.org/10.1055/a-0862-0346 


\section{MAIN RECOMMENDATIONS}

ESGE recommends offering stone extraction to all patients with common bile duct stones, symptomatic or not, who are fit enough to tolerate the intervention.

Strong recommendation, low quality evidence.

ESGE recommends liver function tests and abdominal ultrasonography as the initial diagnostic steps for suspected common bile duct stones. Combining these tests defines the probability of having common bile duct stones.

Strong recommendation, moderate quality evidence.

ESGE recommends endoscopic ultrasonography or magnetic resonance cholangiopancreatography to diagnose common bile duct stones in patients with persistent clinical suspicion but insufficient evidence of stones on abdominal ultrasonography.

Strong recommendation, moderate quality evidence.

ESGE recommends the following timing for biliary drainage, preferably endoscopic, in patients with acute cholangitis, classified according to the 2018 revision of the Tokyo Guidelines:

- severe, as soon as possible and within 12 hours for patients with septic shock
- moderate, within 48-72 hours

- mild, elective.

Strong recommendation, low quality evidence.

ESGE recommends endoscopic placement of a temporary biliary plastic stent in patients with irretrievable biliary stones that warrant biliary drainage.

Strong recommendation, moderate quality of evidence.

ESGE recommends limited sphincterotomy combined with endoscopic papillary large-balloon dilation as the first-line approach to remove difficult common bile duct stones. Strong recommendation, high quality evidence.

ESGE recommends the use of cholangioscopy-assisted intraluminal lithotripsy (electrohydraulic or laser) as an effective and safe treatment of difficult bile duct stones. Strong recommendation, moderate quality evidence.

ESGE recommends performing a laparoscopic cholecystectomy within 2 weeks from ERCP for patients treated for choledocholithiasis to reduce the conversion rate and the risk of recurrent biliary events.

Strong recommendation, moderate quality evidence.

\section{PUBLICATION INFORMATION}

This Guideline is an official statement of the European Society of Gastrointestinal Endoscopy (ESGE). It provides practical advice on how to manage common bile duct stones. The Grading of Recommendations Assessment, Development, and Evaluation (GRADE) system was adopted to define the strength of recommendations and the quality of evidence.

\section{Introduction}

Gallstones are a very common problem in developed countries [1-3]. Most patients with gallstones remain asymptomatic throughout their lifetime $[4,5]$, but $10 \%-25 \%$ of them may develop biliary pain or complications [6-9], with an annual risk of about 2\%-3\% for symptomatic disease [10] and 1\%-2\% for major complications [11]. The development of symptomatic disease and complications is mostly related to the migration of stones into the common bile duct (CBD). Common bile duct stones (CBDSs) may be treated by endoscopic retrograde cholangiopancreatography (ERCP) or surgically during cholecystectomy. The aim of this evidence- and consensus-based Guideline, commissioned by the European Society of Gastrointestinal Endoscopy (ESGE), is to provide practical advice on how to manage patients with CBDSs. It considers diagnostic strategies in patients with suspected CBDSs, as well as the different therapeutic options available for CBDSs.

\section{Methods}

The ESGE commissioned this Guideline (chair J.v.H.) and appointed a guideline leader (G.M.), who invited the listed authors to participate in the project development. The key questions were prepared by the coordinating team (G.M. and G.P.) and then approved by the other members. The coordinating team formed task-force subgroups, each with its own leader, and divided the key topics among these task forces (Appendix $1 \mathrm{~s}$; see online-only Supplementary Material).

Each task force performed a systematic literature search to prepare evidence-based and well-balanced statements on their assigned key questions. The coordinating team independently performed systematic literature searches, with PubMed/Medline, EMBASE, the Cochrane Library, and the internet being finally searched for papers published until April 2018. The search focused on fully published randomized controlled trials (RCTs), meta-analyses, and prospective series. Retrospective analyses, case series, and abstracts were also included if they addressed topics not covered in the prospective studies. The literature search was restricted to papers published in English after 1990.

After further exploration of their content, articles that contained relevant data were then included and summarized in the literature tables for the key topics (Tables 1s-14s). All selected articles were graded by the level of evidence and strength of recommendation according to the GRADE system [12]. Each task force developed a draft and proposed statements on their assigned key questions, which were discussed and voted on during plenary meetings held in February 2017 in Düsseldorf, Germany, and in October 2017 in Barcelona, Spain. In April 


\begin{tabular}{|c|c|}
\hline \multicolumn{2}{|c|}{ ABBREVIATIONS } \\
\hline $\mathrm{ABP}$ & acute biliary pancreatitis \\
\hline ASGE & $\begin{array}{l}\text { American Society for Gastrointestinal } \\
\text { Endoscopy }\end{array}$ \\
\hline CBD & common bile duct \\
\hline CBDS & common bile duct stones \\
\hline $\mathrm{Cl}$ & confidence interval \\
\hline CT & computed tomography \\
\hline DPOC & direct peroral cholangioscopy \\
\hline EHL & electrohydraulic lithotripsy \\
\hline EPLBD & endoscopic papillary large-balloon dilation \\
\hline ERCP & $\begin{array}{l}\text { endoscopic retrograde cholangiopancreato- } \\
\text { graphy }\end{array}$ \\
\hline ESGE & $\begin{array}{l}\text { European Society of Gastrointestinal Endos- } \\
\text { copy }\end{array}$ \\
\hline ESWL & extracorporeal shock wave lithotripsy \\
\hline EUS & endoscopic ultrasonography \\
\hline IOC & intraoperative cholangiography \\
\hline IRR & incidence rate ratio \\
\hline LFT & liver function test \\
\hline MBC & mother - baby cholangioscopy \\
\hline MRCP & $\begin{array}{l}\text { magnetic resonance cholangiopancreato- } \\
\text { graphy }\end{array}$ \\
\hline NR-ERCP & non-radiation ERCP \\
\hline NSAID & nonsteroidal anti-inflammatory drug \\
\hline OR & odds ratio \\
\hline OTS & out of the scope \\
\hline PTBD & percutaneous transhepatic biliary drainage \\
\hline RCT & randomized controlled trial \\
\hline $\mathbf{R} \mathbf{R}$ & relative risk \\
\hline SD & standard deviation \\
\hline SEMS & self-expanding metal stent \\
\hline SOC & single-operator cholangioscopy \\
\hline TTS & through the scope \\
\hline UDCA & ursodeoxycholic acid \\
\hline
\end{tabular}

2018, a draft prepared by the coordinating team was sent to all group members.

After agreement of all group members, the manuscript was reviewed by two members of the ESGE Governing Board, and by two external reviewers and was then sent for further comments to the ESGE National Societies and Individual Members. The manuscript was then submitted to Endoscopy for publication. All authors agreed on the final revised manuscript. This Guideline was issued in 2019 and will be considered for review in 2023 , or sooner if new and relevant evidence becomes available. Any updates to the Guideline in the interim will be noted on the ESGE website: http://www.esge.com/esgeguidelines. html.

\section{General principles}

\subsection{Epidemiology}

Gallstones are common with a prevalence as high as 10\%-15\% in developed countries [1-3] and an overall cumulative incidence of gallstone formation of $0.60 \%$ per year [13].

According to a large Swedish registry [14], the prevalence of CBDSs detected during intraoperative cholangiography (IOC) is $11.6 \%$ in patients with symptomatic gallbladder stones; other prospective studies have described a prevalence of CBDSs detected during IOC ranging from $4.6 \%$ to $12 \%$ in Europe $[15,16]$, and up to $20.9 \%$ in South America [17]. A prevalence of $8 \%-18 \%$ for CBDSs in patients with symptomatic gallbladder stones has been proposed [18].

No studies have focused on the prevalence of CBDSs in patients with asymptomatic gallbladder stones, as most studies are based on IOC during cholecystectomy for symptomatic disease.

\subsection{The natural history of CBDSs and recommended handling}

\section{RECOMMENDATION}

ESGE recommends offering stone extraction to all patients with common bile duct stones, symptomatic or not, who are fit enough to tolerate the intervention.

Strong recommendation, low quality evidence.

The natural history of CBDSs is not well described, but data from the GallRiks study [14] suggest that, if CBDSs are detected, they should be removed to reduce the risk of complications over time: of the 3969 patients with CBDSs on IOC, 594 had their CBDSs left in place. During follow-up, ranging from 0 to 4 years, $25.3 \%$ of patients with CBDSs in situ developed complications (pancreatitis, cholangitis, or obstruction of the bile duct) vs. $12.7 \%$ of patients who had undergone CBDS removal (odds ratio [OR] $0.44,95 \% \mathrm{Cl} 0.35-0.55$ ). The likelihood of an unfavorable outcome increased with the size of the CBDS, but the incidence of complications even for CBDSs less than $4 \mathrm{~mm}$ was $5.9 \%$ vs. $8.9 \%$ for larger CBDSs (OR 0.52 , $95 \% \mathrm{Cl} 0.34-$ $0.79)$.

These data support a strategy of extracting CBDSs regardless of size, although some previous studies have suggested that small unsuspected stones can pass spontaneously without the need for intervention [16, 19-22] (Table 1 s). The spontaneous passage of small CBDSs without serious complications has been documented by Collins [15] in 24 of 46 patients with a filling defect observed on IOC in whom a cystic duct catheter was left in place after laparoscopic cholecystectomy. The asymptomatic migration of small (less than $8 \mathrm{~mm}$ ) stones has also been noted in the interval between diagnosis at endoscopic ultrasonography (EUS) and ERCP [23].

In spite of the absence of controlled studies, some factors favor a policy of stone extraction in asymptomatic CBDSs: the occurrence of unfavorable outcomes is not different in patients 
classified as asymptomatic or symptomatic [14]; the lifetime risk of untreated CBDSs is unknown and may be higher than that reported; severe complications such as cholangitis, pancreatitis, or obstructive jaundice can occur without preceding warning symptoms [24]. A conservative approach can only be considered in patients where the risks of surgical or endoscopic CBDS extraction are higher than the risks of leaving stones in situ. When offering stone extraction to asymptomatic patients with CBDSs, patients should be made aware of the limited evidence regarding this recommendation and of the risk of ERCP, which may be elevated in asymptomatic patients [25].

\section{Defining the risk of having CBDSs}

\subsection{Initial evaluation}

\section{RECOMMENDATION}

ESGE recommends liver function tests and abdominal ultrasonography as the initial diagnostic steps for suspected common bile duct stones. Combining these tests defines the probability of having common bile duct stones. Strong recommendation, moderate quality evidence.

Patients at risk of having CBDSs, such as patients with gallstones who present with symptoms, undergo non-invasive tests such as liver function tests (LFTs) and abdominal ultrasound as triage to determine the need for further evaluations to confirm the presence of CBDSs.

A recent systematic review including five studies assessed the diagnostic accuracy of LFTs (1 study) and ultrasonography (5 studies) for CBDSs [26]. All studies were of poor methodological quality. The sensitivities of bilirubin (cutoff $>22.23 \mu \mathrm{mol} / \mathrm{L}$ or $>1.3 \mathrm{mg} / \mathrm{dL}$ ) and alkaline phosphatase (cutoff $>125 \mathrm{U} / \mathrm{L}$ ) for CBDSs were $84 \%$ (95\% confidence interval $[\mathrm{Cl}] 64 \%-95 \%$ ) and $91 \%$ ( $95 \% \mathrm{Cl} 74 \%$ - 99\%), respectively; the specificities were $91 \%$ (95\%Cl 86\%-94\%) and 79\% (95\%Cl 74\%-84\%), respectively. Regarding ultrasonography, sensitivity was $73 \%$ (95\%Cl $44 \%-$ $95 \%)$ and specificity was $91 \%(95 \% \mathrm{Cl} 84 \%-95 \%)$. Ultrasonography findings were considered positive if there was visualization of CBDSs and/or CBD dilatation.

Multidetector multiphase computed tomography (CT), when used to investigate patients with CBDSs, had a sensitivity of $78 \%$ and a specificity of $96 \%$ in a retrospective study [27]. The size and composition of the stones significantly affects CT accuracy, which is significantly lower when stones are less than $5 \mathrm{~mm}$ (56.5\% vs. $81.2 \%$ ) or have a similar density to bile [28]. Coronal reconstruction does not increase the diagnostic efficiency of CT scanning [29].

The pretest probability of CBDSs in suspected patients is essential to select which patients will benefit most from a more accurate assessment. Several predictive models have been developed combining clinical, biochemical, and ultrasonography findings in order to identify high risk patients [30-34] (Table 2s).
The risk of having CBDSs in spite of normal LFTs and ultrasonography has been adequately evaluated in two studies $[35,36]$. In a large study including 765 patients with ERCPproven CBDSs, 541 had previously documented LFTs and 29 (5.4\%) had normal LFTs. Age more than 55 years and the presence of pain were independently associated with normal LFTs in patients with CBDSs [35]. A more recent retrospective study including 413 patients with gallstones who underwent ultrasonography and magnetic resonance cholangiopancreatography (MRCP) for suspected CBDSs showed that 109/413 (26.3\%) had CBDSs revealed on the MRCP, but in 7/109 (6.4\%) ultrasonography and LFTs (one or more of total bilirubin, ALP, AST, ALT, or GGT) were normal [36] (Table 2s).

\subsection{Role of EUS and MRCP}

RECOMMENDATION

ESGE recommends endoscopic ultrasonography or magnetic resonance cholangiopancreatography to diagnose common bile duct stones in patients with persistent clinical suspicion but insufficient evidence of stones on abdominal ultrasonography.

Strong recommendation, moderate quality evidence.

The diagnostic accuracy of EUS and MRCP for the detection of CBDSs has been widely investigated. Meeralam and co-workers in a recent meta-analysis of five head-to-head studies [37] demonstrated that diagnostic accuracy was high for both methods (sensitivity $97 \%$ vs. $90 \%$ and specificity $87 \%$ vs. $92 \%$ for EUS and MRCP, respectively), but the overall diagnostic OR of EUS was significantly higher $(P=0.008)$. They showed that this was mainly because of the significantly higher sensitivity of EUS, as compared with that of MRCP, especially in the detection of small stones, while the specificity was not significantly different. High accuracy for both methods was demonstrated by another meta-analysis including 18 studies (2 comparative, 5 evaluating MRCP alone and 11 EUS alone) [38]. Sensitivity and specificity were respectively $95 \%(95 \% \mathrm{Cl} 91 \%-97 \%)$ and $97 \%$ (95\%Cl $94 \%-99 \%)$ for EUS, and $93 \%$ (95\%Cl 87\%-96\%) and $96 \%$ (95\%Cl $90 \%-98 \%)$ for MRCP.

Various considerations may help to select the most adequate procedure if both are available and the patient does not present any factors that would impede MRCP, such as claustrophobia, obesity, cardiac pacemaker, or metal clips. Sonnemberg and colleagues [39], performing a threshold analysis on costs, concluded that, for a pretest probability of CBDSs $<40 \%$, MRCP would represent the procedure of choice. For a pretest probability in the range $40 \%-91 \%$, EUS should be the preferred imaging modality, because it allows an ERCP to be performed in the same session if the EUS results are positive for CBDSs. However, the applicability of their results is limited because they are strictly influenced by the costs of each procedure and local rules of reimbursement. Furthermore, logistic issues regarding the scheduling of an EUS and an ERCP during the same examination slot should be taken into consideration. The minimally invasive nature of MRCP, its suitability if there is al- 


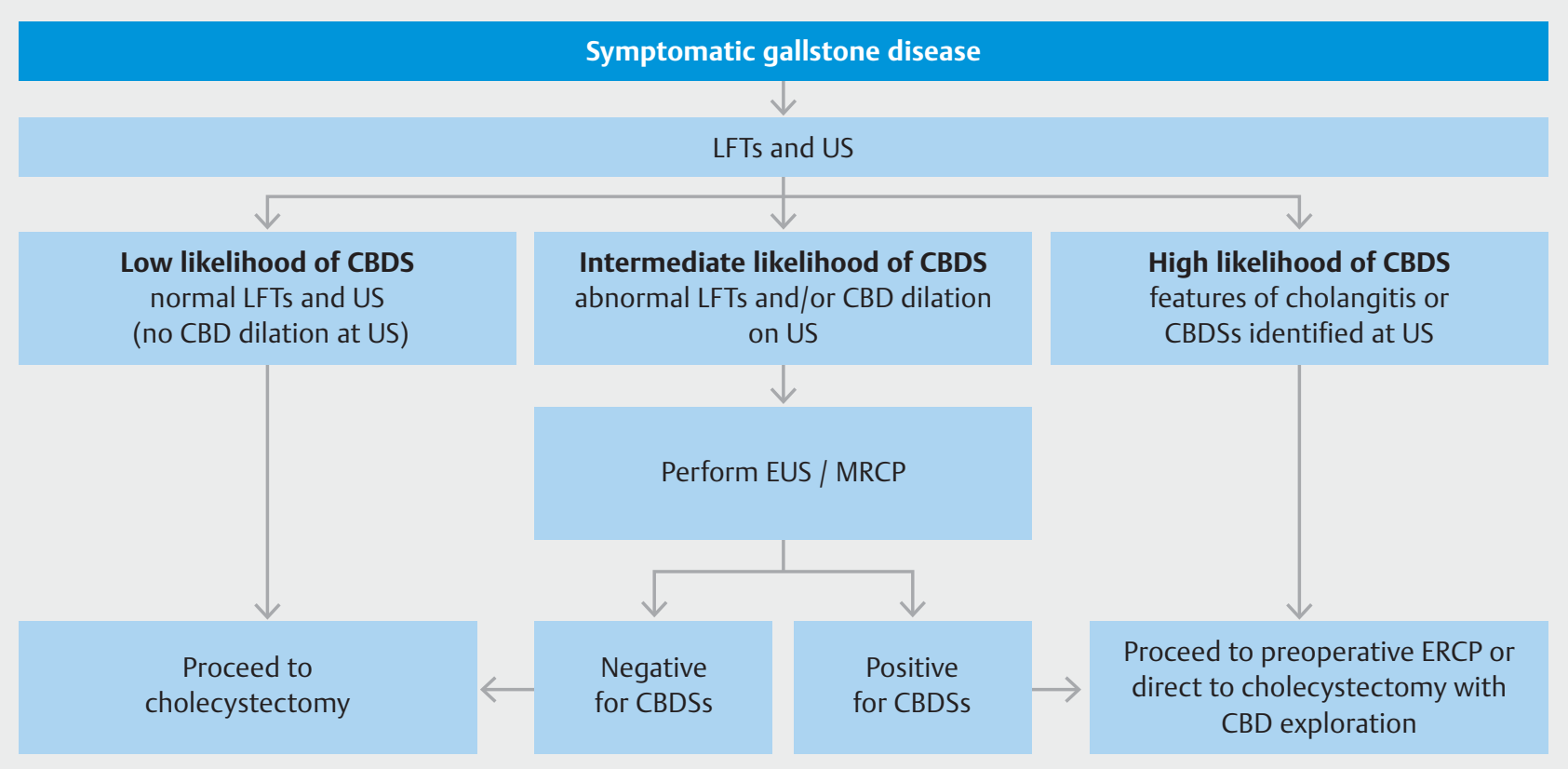

- Fig. 1 Diagnostic algorithm for suspected common bile duct stones (CBDSs). LFTs, liver function tests; US, ultrasound; CBD, common bile duct; EUS, endoscopic ultrasonography; MRCP, magnetic resonance cholangiopancreatography; ERCP, endoscopic retrograde cholangiopancreatography.

tered gastroduodenal anatomy, and its ability to visualize the whole biliary tree should also be considered when deciding between the two methods.

\subsection{An algorithm for investigating suspected CBDSs}

-Fig. 1 depicts an algorithm for investigating suspected CBDSs. ERCP can be performed in patients without cholangitis only when CBDSs are visible on imaging modalities that have a high specificity. Normal LFTs and ultrasonography indicate a low risk of CBDSs and no further evaluations are recommended, unless the patient continues to have symptoms that suggest CBDSs. All other pictures depict an intermediate risk of CBDSs, which should prompt further investigation by EUS or MRCP. In the absence of a morphological diagnosis of CBDSs, ERCP should be performed immediately only in patients with a clinical picture of cholangitis (see section 8.1).

\section{Performing ERCP}

\subsection{Antibiotic prophylaxis}

\section{RECOMMENDATION}

ESGE suggests against the use of routine antibiotic prophylaxis before ERCP for bile duct stones.

Weak recommendation, moderate quality evidence.

The ERCP procedure is often associated with the occurrence of bacteremia [40], which is mostly transient. The occurrence of cholangitis is an infrequent event, which occurs mainly in a subgroup of patients at higher risk, such as those with biliary obstruction and incomplete biliary drainage [41].

The role of antibiotic prophylaxis in reducing the rate of cholangitis has been evaluated by several RCTs, which differed significantly in terms of type of antibiotic, duration of administration, and indications for ERCP [42 - 47] and three meta-analyses (Table 3 s) [48-50].

The most recent meta-analysis of nine RCTs [50] (1573 patients) indicated that antibiotic prophylaxis could reduce bacteremia and may prevent cholangitis and septicemia in patients undergoing elective ERCP. However, in random-effects metaanalyses, only the effect on bacteremia remained significant; if ERCP resolved the biliary obstruction at the first procedure, there was no significant benefit in using antibiotic prophylaxis to prevent cholangitis (relative risk [RR] 0.98, $95 \% \mathrm{Cl} 0.35-$ 2.69, only three trials) [50].

Cotton et al. [51] reported in a retrospective series of 11484 ERCPs performed over 11 years that, in spite of a progressive reduction in the use of antibiotic prophylaxis over the years (from $95 \%$ to $25 \%$ of ERCP patients), the incidence of infections decreased from $0.48 \%$ to $0.25 \%$. In the multivariate model, endoscopic treatment of CBDSs was not associated with an increased risk of developing cholangitis after ERCP. All these data suggest that not all patients benefit from antibiotic prophylaxis and that patients with CBDSs should not routinely receive antibiotic prophylaxis before ERCP (Table $3 \mathbf{s}$ ).

Patients with ongoing acute cholangitis should already be receiving antibiotics at the time of intervention and additional antibiotics are not recommended. 
Antibiotic prophylaxis should be considered for patients with refractory CBDSs undergoing extracorporeal shock wave lithotripsy (ESWL) for CBD clearance [52,53]. No data are available for patients undergoing cholangioscopy-assisted lithotripsy; nevertheless, antibiotic prophylaxis is likely to be advisable as two recent prospective studies have demonstrated that cholangioscopy per se may carry a risk of bacteremia that ranges from $8.8 \%$ to $13.9 \%$ and that up to $9.7 \%$ of patients may develop infective complications despite the use of postprocedure antibiotics [54]. Biopsy sampling, older age, previous stent placement, and laser lithotripsy or electrohydraulic lithotripsy (EHL) were likely to increase the risk of developing either infection or persistent bacteremia.

Antibiotic prophylaxis in some special conditions, such as in liver transplant patients, was considered to be out of the scope of this guideline.

\subsection{Gaining access to the biliary tree}

\section{RECOMMENDATION}

ESGE recommends that an adequate exit for the stones that are to be removed should be provided according to the papilla and common bile duct anatomy and the stone size.

Strong recommendation, low quality evidence.

The various technical aspects, either of deep biliary cannulation or endoscopic sphincterotomy, have been reviewed in other guidelines $[55,56]$. A critical step to obtain successful stone extraction is to provide an adequate exit for the stones that are to be removed by endoscopic sphincterotomy alone, endoscopic papillary balloon dilation alone, or a combination of both [55,57]. Papillary balloon dilation alone however remains unpopular and is not advocated for routine use as it is associated with a lower technical success for stone clearance, the need for mechanical lithotripsy more frequently than with endoscopic sphincterotomy, and a presumed increased risk of pancreatitis $[55,58,59]$. At present, the use of primary papillary balloon dilation without endoscopic sphincterotomy is considered mainly in patients with coagulopathy or with altered anatomy who have stones smaller than $8 \mathrm{~mm}$ [55]. The appropriate length of endoscopic sphincterotomy should be adjusted according to the papillary anatomy and stone size. Data on the effect of endoscopic sphincterotomy length on the rate of stone recurrence are presently contradictory [60, 61].

\subsection{Stone extraction}

RECOMMENDATION

ESGE recommends that balloon and basket catheters are equally effective and safe for common bile duct stone removal.

Strong recommendation, moderate quality evidence.
Two multicenter RCTs have compared the efficacy of balloon vs. basket catheters for the extraction of CBDSs sized $\leq 10 \mathrm{~mm}$ or $<11 \mathrm{~mm}$ after endoscopic sphincterotomy [62,63]. In one RCT (158 patients), the balloon catheter achieved a higher clearance rate than the basket catheter (92.3\% vs. $80.0 \%$ ) [62]. The other RCT (184 patients) reported similar efficacies for basket and balloon catheters for stone extraction, but a stone diameter of $<6 \mathrm{~mm}$ was independently associated with failed stone removal within 10 minutes using a basket catheter, because of the inability to grasp the stone with the basket [63]. No differences in safety were reported in the two studies.

Stone extraction baskets and balloons are commercially available in various configurations. As yet, no comparative studies between various models of basket catheters exist [64]. In general, choosing which device to use depends mainly on the anatomy of the bile duct, the stone characteristics, financial considerations, and personal preferences.

\subsection{Biliary stenting for incomplete removal of CBDSs}

\section{RECOMMENDATION}

ESGE recommends endoscopic placement of a temporary biliary plastic stent in patients with irretrievable biliary stones that warrant biliary drainage.

Strong recommendation, moderate quality of evidence.

Endoscopic sphincterotomy with stone extraction has success rates of $80 \%-90 \%$ in the treatment of CBDSs [65]. When CBDSs cannot be completely removed, a plastic stent is often placed to relieve the obstruction, before a second attempt at stone extraction is made or a subsequent surgical intervention is undertaken. An indwelling endoprosthesis may reduce the volume and number of stones, as reported by nine studies (three prospective [66-68] and six retrospective [69-74]) involving a total of 364 patients (Table $4 \mathrm{~s}$ ). The success rate for stone removal after previous ERCP with biliary stenting has been reported to range from $44 \%$ to $96 \%$ (Table 5s) [66-73, 75, 76].

The mechanism by which stones change in number and size is unclear. It is likely that continuous friction between the plastic stent and the stones produces stress forces that facilitate the disintegration of stones and reduce their size [71].

There are no studies comparing the different types of biliary plastic stents or plastic vs. metal stents. Similarly, there are no specific prospective comparative data with regard to whether one or more than one biliary stent is preferable in patients with incomplete stone removal. In the only retrospective published study, 64 elderly patients ( $\geq 65$ years) with large ( $\geq 20 \mathrm{~mm}$ ) or multiple $(\geq 3)$ CBDSs underwent placement of single or double plastic stents at the time of initial ERCP. Approximately 3 months later, stone removal was attempted at a second ERCP using standard techniques. Double plastic biliary stenting (7 or $8.5 \mathrm{Fr}$ ) was superior to single stenting $(8.5 \mathrm{Fr})$ in maintaining higher 3 -month stent patency rates $(P$ $=0.008$ ), but was similar in terms of reducing the size and 
number of stones [77]. No differences in complications were found.

In recent years, some studies with small patient series have evaluated the management of incomplete stone removal using fully covered self-expanding metal stents (SEMSs) (Table6 $\mathbf{s}$ ) [78-80]. In the largest retrospective case series [80], 44 patients received covered SEMSs (diameter $10 \mathrm{~mm}$, length 60 $\mathrm{mm}$ ). After a median in-stent duration of 8 weeks, 36/42 stents $(82 \%)$ were removed with successful duct clearance. The median post-procedure follow-up was 15 months. Four patients (9\%) developed post-ERCP pancreatitis (mild in 3, moderate in 1), two patients (4\%) developed post-procedure cholangitis, and one ( $2 \%$ ) hematemesis. During follow-up, 10 patients $(22.7 \%)$ had incidental stent migration (distally in 6, proximally in 4), but in none of them was it clinically significant, with all being discovered at the time of subsequent ERCP.

At present, covered SEMSs can be considered as an alternative to plastic stents to drain the bile ducts after unsuccessful stone removal, but there are uncertainties over how long the stents should be left in place and the cost-benefit ratio of the treatment.

\subsection{Timing of stent removal/exchange}

\section{RECOMMENDATION}

ESGE recommends that a plastic stent placed because of incomplete common bile duct stone clearance should be removed or exchanged within 3-6 months to avoid infectious complications.

Strong recommendation, moderate quality of evidence.

\section{RECOMMENDATION}

ESGE recommends against the use of definitive biliary stenting in patients with incomplete common bile duct stone clearance because of the high complication and mortality rates on medium-term follow-up.

Strong recommendation, moderate quality of evidence.

Intervals of 3-6 months for routine ERCP and stent change are commonly recommended to reduce the rate of complications, mainly cholangitis $[70,76]$. One randomized prospective study including 78 patients with primary failure for biliary stone removal who had undergone insertion of a $10-\mathrm{Fr}$ plastic stent compared two different managements: either systematic stent exchange every 3 months or stent exchange on demand if symptoms occurred. Cholangitis was significantly more frequent in the group with on-demand stent exchange (35.9\% vs. $7.7 \%$; $P<0.03)[81]$.

Definitive stenting has been suggested for difficult CBDSs in the elderly with co-morbidities and a limited life expectancy, given that ERCP in patients aged $>90$ years may carry risks of bleeding, cardiopulmonary events, and mortality that are increased two to three fold (incidence rate ratio [IRR] $2.4,95 \% \mathrm{Cl}$ $1.1-5.2$; IRR 3.7, $95 \% \mathrm{Cl} 1.0-13.9$; and IRR 3.8, 95\%Cl $1.0-$
14.4 , respectively), and that patients aged $>80$ years had a two-fold risk of procedure-related death (IRR 2.4; $95 \% \mathrm{Cl} 1.3$ 4.5) [82]. However, definitive stenting for CBDSs should be approached with caution. Six series, including 230 patients [8388 ], have reported a complication rate for definitive biliary stenting, mainly cholangitis, of $34 \%-63 \%$, with a $2.3 \%-23.5 \%$ mortality rate during $16-39$ months of follow-up (Table $7 \mathrm{~s}$ ).

\subsection{Role of dissolution therapy}

\section{RECOMMENDATION}

EGSE suggests against the use of ursodeoxycholic acid or other choleretic agents, either for the treatment of CBDSs or to prevent the recurrence of CBDSs after endoscopic clearance.

Weak recommendation, moderate quality of evidence.

Ursodeoxycholic acid (UDCA) with or without terpene preparation (Rowachol) has been suggested as a complementary treatment to induce stone reduction when used together with biliary endoprostheses, but in two RCTs the addition of UDCA therapy to endoprosthetic treatment showed no effect on stone size reduction or successful duct clearance $[66,68]$.

UDCA has been administered with the aim of reducing the rate of stone recurrence after successful removal of CBDSs in patients with risk factors such as CBD dilatation, delayed biliary emptying (biliary stricture, papillary stenosis), or the presence of gallstones, a periampullary diverticulum, or systemic diseases that cause stone formation [89-91]. Two RCTs have investigated this issue and both revealed no significant difference regarding stone recurrence $[92,93]$.

\section{Difficult stones}

"Difficult" biliary stones are defined according to their diameter $(>1.5 \mathrm{~cm})$, number, unusual shape (barrel-shaped), or location (intrahepatic, cystic duct), or because of anatomical factors (narrowing of the bile duct, distal to the stone, sigmoid-shaped CBD, stone impaction, shorter length of the distal CBD, or acute distal $\mathrm{CBD}$ angulation $<135^{\circ}$ ) $[94,95]$. Clearance of a difficult stone cannot usually be obtained using standard techniques, so multiple procedures and additional interventional techniques (large-balloon dilation, mechanical lithotripsy, cholangioscopy-assisted electrohydraulic/laser lithotripsy, or ESWL) may be required [96]. 


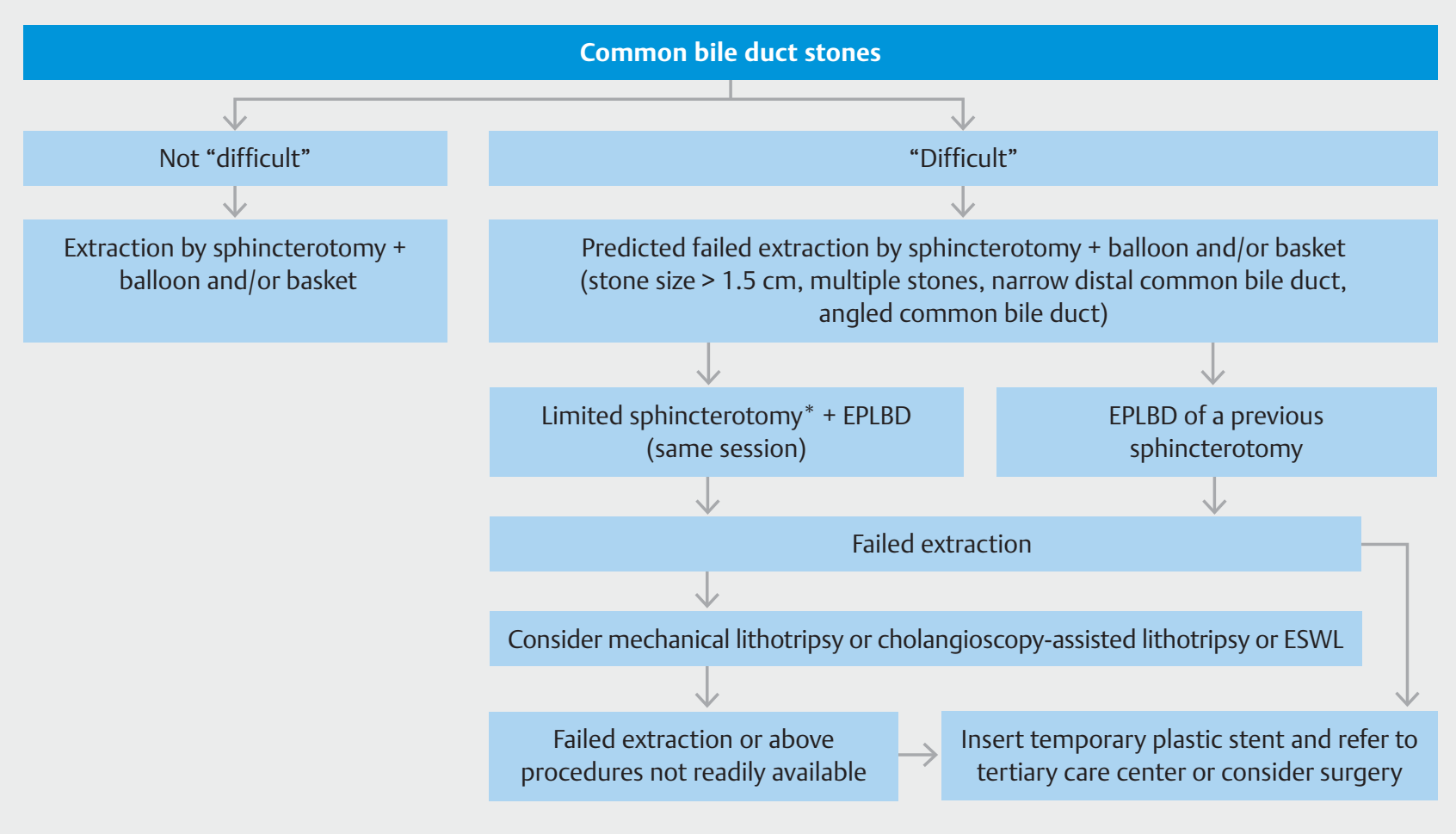

- Fig. 2 Therapeutic algorithm for management of common bile duct stones when ERCP is selected as the primary treatment. ERCP, endoscopic retrograde cholangiopancreatography; EPLBD, endoscopic papillary large-balloon dilation (12-20 mm); ESWL, extracorporeal shock wave lithotripsy.

* EPLBD without sphincterotomy suggested in those with coagulopathy.

\subsection{Gaining access to the biliary tree and basic treatment for the management of difficult stones}

\section{RECOMMENDATION}

ESGE recommends limited sphincterotomy combined with endoscopic papillary large-balloon dilation as the first-line approach to remove difficult common bile duct stones.

Strong recommendation, high quality evidence.

Since the original description in 2003 by Ersoz et al., the use of endoscopic papillary large-balloon dilation (EPLBD) after endoscopic sphincterotomy has become widespread for the management of difficult CDBSs [97]. Overall, seven RCTs [98104] and five meta-analyses [105 - 109] have compared the efficacy and safety of EPLBD with endoscopic sphincterotomy vs. endoscopic sphincterotomy alone (Table $8 \mathrm{~s}$ ).

In summary, endoscopic sphincterotomy+EPLBD reduces the need for mechanical lithotripsy by about $30 \%-50 \%$ in comparison with endoscopic sphincterotomy alone [100,102,103], while the overall rate of successful stone removal remains identical [105-108]. The rate of major adverse events, mainly pancreatitis, bleeding, and perforation, between the two groups was similar in 6 of 7 RCTs [99-104], whereas it was significantly lower for EPLBD plus endoscopic sphincterotomy compared with endoscopic sphincterotomy alone in the study by Stefani- dis et al. [98]. In a systematic review (30 studies considered), the rate of overall adverse events (pancreatitis, bleeding, perforation) was lower for endoscopic sphincterotomy with EPLBD than for endoscopic sphincterotomy alone (8.3\% vs. $12.7 \%$, OR $1.60 ; P<0.001)[110]$.

Based on these data, if large bile duct stones are seen on ERCP or cross-sectional imaging, endoscopic sphincterotomy combined with EPLBD can be used as a first-line approach to facilitate difficult biliary stone removal [111]. Another possible indication for performing EPLBD is the treatment of recurrent CBDSs in individuals with a previous endoscopic sphincterotomy because extension of an endoscopic sphincterotomy may be associated with a high risk of bleeding and perforation [112-115] ( Fig. 2).

EPLBD can be performed after either a large $[97,98,114$, 116-121] or limited endoscopic sphincterotomy [99,120, $122-127]$. A multicenter retrospective analysis from Asia including 946 patients [120] found large endoscopic sphincterotomy before EPLBD to be independently associated with an increase in overall adverse events (OR 3.4, 95\% Cl 1.8-6.6; $P<$ $0.001)$. The risk of bleeding was higher in the large vs. limited endoscopic sphincterotomy group (OR 6.2, 95\%Cl 2.4-16.3; $P<0.001)$. Perforation was found in only nine patients but it was fatal in three of them. Although only distal CBD stricture and not size of endoscopic sphincterotomy was an independent predictor of perforation, two of the three fatal cases were associated with a large endoscopic sphincterotomy. A 
recent literature review suggested performing a small or midsized endoscopic sphincterotomy ( $1 / 3$ to $1 / 2$ of the distance to the papillary roof) rather than a large one before EPLBD [128]. Nevertheless, in real life most endoscopists decide to perform EPLBD when their attempts to remove the stones have failed after having already performed a complete endoscopic sphincterotomy.

EPLBD is performed with a dilation balloon diameter that ranges from 12 to $20 \mathrm{~mm}$. Criteria for deciding the balloon size for EPLBD have not been specifically evaluated in prospective studies. In most published studies, the diameter of the distal part of the CBD has been used as the criterion to select the size of the balloon $[98-100,120,121]$. The risk of perforation increases when the diameter of the balloon is larger than the diameter of the distal part of the CBD and in the presence of a stricture [111].

The vast majority of studies have reported a dilation duration of $10-180$ seconds from the disappearance of the waist, with only three studies reporting a duration in excess of $60 \mathrm{sec}$ onds [110]. One RCT has demonstrated that the rate of complications is similar whether EPLBD duration is either 30 or 60 seconds [121]. Moreover, a meta-analysis has demonstrated that a short duration ( $<1$ minute) vs. a long duration ( $\geq 1$ minute) for EPLBD does not significantly affect the rate of CBD clearance [105]. According to these data, the duration of balloon dilation should be between 30 and 60 seconds from the disappearance of the waist [111].

\subsection{Mechanical lithotripsy}

\section{RECOMMENDATION}

ESGE recommends mechanical lithotripsy for difficult stones when sphincterotomy plus endoscopic papillary large-balloon dilation has failed or is inappropriate. Strong recommendation, moderate quality evidence.

Mechanical lithotripsy is the simplest available method of fragmenting CBDSs. It consists of entrapping the stone within a reinforced basket and then crushing it by closing the basket against a metal spiral sheath. Two techniques of mechanical lithotripsy are used: out of the scope (OTS) and through the scope (TTS). The OTS technique represents a "salvage" procedure to be performed when a standard basket engages a large stone and becomes impacted in the papilla, while the TTS technique is preferred in elective cases.

Mechanical lithotripsy has been reported to be an effective and safe technique, but multiple sessions may be required. The reported success rates range between $76 \%$ and $91 \%$ and overall complications from $3 \%$ to $34 \%$ with minimal mortality [129-134] (Table 9s). Three studies have evaluated the predictors of mechanical lithotripsy failure using multivariate analysis. In a retrospective study [130], stone size was the only variable that affected the success rate. A subsequent prospective study [129] reported that stone size should be considered together with the diameter of the bile duct, suggesting that only the presence of stone impaction significantly predicted the fail- ure of mechanical lithotripsy. In another more recent retrospective study [132], stone impaction, stone size $>30 \mathrm{~mm}$, and stone to CBD diameter ratio $>1$ were significant predictors of mechanical lithotripsy failure.

The most common and feared complications of mechanical lithotripsy are entrapment of the basket, a broken basket, a traction wire fracture, or a broken handle. In a multicenter study by Thomas et al. [135], including 643 patients and using the TTS technique, the incidence of mechanical lithotripsyrelated technical complications was 3.5\%. These complications are usually treated by other types of lithotripsy (OTS, ESWL, or cholangioscopy-assisted lithotripsy), sphincterotomy extension, or stenting.

\subsection{Cholangioscopy-assisted lithotripsy}

\section{RECOMMENDATION}

ESGE recommends the use of cholangioscopy-assisted intraluminal lithotripsy (electrohydraulic or laser) as an effective and safe treatment of difficult bile duct stones. Strong recommendation, moderate quality evidence.

\section{RECOMMENDATION}

ESGE suggests that the type of cholangioscopy and lithotripsy should depend on local availability and experience. Weak recommendation, low quality evidence.

Intraductal shock wave lithotripsy represents an alternative method to fragment bile stones and allow their removal. There are two methods of generating shock waves in a fluid, using either a bipolar probe capable of generating a spark in the case of EHL or a pulsed dye laser system in the case of laser lithotripsy. Both EHL and laser lithotripsy are preferably performed under direct visualization with cholangioscopic guidance.

There are three major techniques for cholangioscopy: (i) a dual-operator dedicated mother - baby cholangioscopic (MBC) system; (ii) a single-operator catheter-based cholangioscopic system (SOC); and (iii) direct use of an ultraslim endoscope or slim gastroscope (direct peroral cholangioscopy [DPOC]). The procedures vary with respect to the number of operators, maneuverability, image quality, and method of access, resulting in variable success rates. A detailed ESGE technology review on cholangioscopy techniques was published recently [136]. All three techniques allow laser lithotripsy and EHL.

Korrapati et al. have reviewed the efficacy of peroral cholangioscopy for difficult bile duct stones [137]. They estimated an overall rate of stone clearance of $88 \%$ (95\% Cl $85 \%-91 \%)$, with SOC showing a high technical success rate. No attempt was made to compare EHL and laser lithotripsy.

Both EHL and laser lithotripsy are effective methods for the removal of difficult bile duct stones, with a $69 \%$ - $81 \%$ clearance rate in one session and a $97 \%-100 \%$ clearance rate after multiple sessions [138-141]. However, no direct comparisons between the different methods have been published. In one 
recent $R C T$, patients with bile duct stones $>1 \mathrm{~cm}$ were treated with either laser lithotripsy or conventional therapy (included EPLBD and mechanical lithotripsy) and achieved one-session endoscopic clearance rates of $93 \%$ and $67 \%$, respectively [142].

When looking at the rough data of Korrapati et al. [137], the complication rate ranged between $0 \%$ and $25 \%$ (mean $7 \%, 95 \%$ $\mathrm{Cl} 6 \%-9 \%$ ). Cholangitis is the most frequently reported complication [139-141]. Pancreatitis is a rare complication, probably owing to the high percentage of pre-existent sphincterotomies [139].

Overall, the available data suggest that intraluminal lithotripsy is an effective and safe method to treat difficult biliary stones (Table 10 s; $>$ Fig. 2), but there are no data supporting the superiority of one method over another.

\subsection{Extracorporeal shock wave lithotripsy}

\section{RECOMMENDATION}

ESGE suggests considering extracorporeal shock wave lithotripsy when conventional techniques have failed to achieve bile duct clearance and the intraluminal lithotripsy techniques are not available.

Weak recommendation, low quality evidence.

ESWL uses electrohydraulic or electromagnetic energy to generate shock waves that then travel through the soft tissues of the body to fragment CBDSs [143].

ESWL is a complex and technically demanding procedure. A nasobiliary drain is inserted to allow fluoroscopic identification and targeting of CBDSs and to perform continuous irrigation of the bile duct with saline during ESWL. In addition, multiple ESWL sessions and subsequent ERCP procedures to extract stone fragments are required.

Ductal clearance rates of $70 \%-90 \%$ have been reported with ESWL [52, $144-150]$.

Several controlled trials have compared ESWL with EHL or laser lithotripsy for stone disruption. These studies suggest that the efficacy of final duct clearance with laser lithotripsy is superior to that of ESWL $(83 \%-97 \%$ vs. $53 \%-73 \%)[146,151]$, while it is similar for EHL and ESWL (74\% vs. 78.5\%) [145].

ESWL-related adverse events range from $9 \%$ to $35.7 \%$, including mostly cholangitis and pancreatitis $[143,145,146$, $152,153]$. Minor side effects such as pain, local hematoma formation, and microhematuria are common.

\section{Endoscopic CBDS management and surgery}

ERCP with stone clearance represents the primary and definitive treatment in patients with CBDSs and previous cholecystectomy. In patients with CBDSs and in situ gallbladder, both the management of CBDSs and gallbladder removal should be considered.

When ERCP is the selected technique to treat CBDSs, different options are available with regards to the sequencing of endoscopy and surgery. Basically, ERCP can be performed prior to (preoperative ERCP), during ongoing (intraoperative ERCP), or after (post-operative ERCP) cholecystectomy. Preoperative ERCP is most commonly practiced, as it is highly effective and both the endoscopist and the surgeon treat the patient in an environment that is tailored to their own needs and routines.

\subsection{The sequential strategy}

\section{RECOMMENDATION}

ESGE recommends performing a laparoscopic cholecystectomy within 2 weeks from ERCP in patients treated for choledocholithiasis to reduce the conversion rate and the risk of recurrent biliary events.

Strong recommendation, moderate quality evidence.

Laparoscopic cholecystectomy represents the standard treatment for patients with CBDSs and gallbladder stones following endoscopic CDBS clearance. A Cochrane review in 2007 [154], which considered five RCTs involving 662 patients treated for choledocholithiasis with cholecystolithiasis, revealed an advantage of cholecystectomy. Over a follow-up time varying from 17 months to more than 5 years, mortality was higher in the wait-and-see group compared with the cholecystectomy group (14.1\% vs. $7.9 \%$; RR $1.78,95 \% \mathrm{Cl} 1.15-2.75)$ and the difference persisted when only patients at high surgical risk were considered.

Similarly, endoscopic sphincterotomy followed by "wait and see" also resulted in a higher risk of biliary events, such as cholangitis, pancreatitis, jaundice, and biliary colic, as well as a higher risk for repeated biliary intervention (i.e. ERCP or percutaneous procedure): $35 \%$ of the patients managed with endoscopic sphincterotomy followed by "wait and see" eventually underwent rescue cholecystectomy. The outcome of rescue cholecystectomy in patients with an ASA > 3 was not significantly different compared to elective cholecystectomy; however, patients unfit for surgery (i.e. ASA 4 and 5) were excluded in three of the five selected RCTs [155-157]. In the study by Suc et al. [158], $20 \%$ of the included patients were classified as ASA 3-4, and mortality was not significantly different between the two groups in the intention-to-treat analysis (3.1 vs. $0.9 \%$ ). Also, in the RCT by Targarona et al. [159], mortality was not significantly different between the groups but, in the multivariate analysis, age, and not surgical risk, was an independent predictor of mortality.

Laparoscopic cholecystectomy after ERCP with endoscopic sphincterotomy is more difficult and when compared to standard laparoscopic cholecystectomy is mostly associated with a higher conversion rate and a higher rate of recurrent biliary events $[157,160,161]$. In this way, the timing of cholecystectomy performance after ERCP is a critical issue [155, 157, 162 167] (Table 11s). The timing of cholecystectomy may be defined as early, delayed, or on demand, but definitions of "early" or "delayed" differ among the studies. In general, with the exception of the study by Donkervoort et al. [168], where the timing of cholecystectomy did not affect the outcomes, conversion 
rate results are lower in the "early group" in all studies (4\% - $23 \%$ vs. $8 \%-55 \%$ ); recurrent biliary events are lower when the laparoscopic cholecystectomy is performed "early" vs. "delayed or on demand" ( $2 \%-10 \%$ vs. $24 \%-47 \%$ ) [155, $157,162-167]$. Overall, data are in favor of "early" laparoscopic cholecystectomy, but the exact timing remains controversial; despite this, waiting no longer than 2 weeks to perform laparoscopic cholecystectomy after ERCP seems to be advisable.

In patients with acute biliary pancreatitis (ABP) and in situ gallbladder, cholecystectomy is recommended to avoid a recurrence of pancreatitis. Some of these patients may have previously undergone ERCP and endoscopic sphincterotomy. The timing of cholecystectomy in mild ABP has been examined in two RCTs that randomized patients either to cholecystectomy within 48 hours of admission vs. after resolution of abdominal pain and normalizing trend of laboratory enzymes $(n=50)$ [169], or to cholecystectomy during the same admission vs. 4 weeks later $(n=266)$ [170]. Both studies concluded in favor of early cholecystectomy because it prevents recurrent gallstonerelated complications (one study), shortens hospitalization (one study), and is equally safe (both studies). Similar conclusions were reached in a meta-analysis (eight cohort studies and one RCT, 998 patients) [171]. For severe ABP, data are limited and, based on observational studies $[172,173]$, it is recommended that cholecystectomy is performed once peripancreatic collections and local complications have resolved, generally beyond 6 weeks, to minimize the risk of infection in the peripancreatic collection.

In patients who do not undergo cholecystectomy following ABP, endoscopic biliary sphincterotomy reduces biliary events, in particular pancreatitis, during follow-up $[171,174,175]$. The most recent retrospective study (1119 patients) found that recurrent pancreatitis developed in $8.2 \%$ vs. $17.1 \%$ of patients with their gallbladder left in situ after ABP who had ERCP vs. no ERCP, respectively [174]. However, the gallbladder should be left in situ only in patients who are unfit for surgery as a meta-analysis (five RCTs, 662 patients) has shown that endoscopic CBD clearance alone is inferior to prophylactic cholecystectomy associated with CBD clearance in terms of mortality and recurrent biliary events [154].

\subsection{Intraoperative ERCP}

\section{RECOMMENDATION}

ESGE suggests considering intraoperative rendezvous ERCP in patients with common bile duct stones undergoing cholecystectomy.

Weak recommendation, moderate quality evidence.

Intraoperative ERCP can be performed during laparoscopic cholecystectomy when an IOC demonstrates the presence of CBDSs; alternatively, it can be planned either as a one-stage approach in the treatment of combined cholecysto-choledocholithiasis or after the failure of a preoperative endoscopic attempt at CBDS clearance.
Conventional ERCP can be performed intraoperatively, but it exposes the patient to similar risks to a conventional ERCP performed preoperatively, albeit it is performed during the same anesthesia [176,177]. Conversely, intraoperative ERCP with rendezvous cannulation offers the advantages of being a single-stage procedure and decreasing the risk of post-ERCP pancreatitis. Although each individual clinical trial is underpowered to validate this, there are six RCTs [176, 178 - 182] and approximately 15 observational studies pointing in the same direction [177, 183 - 197] (Tables 12s and 13 s). These results have been confirmed by six recent meta-analyses [198-202]. The most recent of these, comparing intraoperative rendezvous ERCP with sequential management, mainly laparoscopic cholecystectomy and preoperative ERCP, reported equal efficacy in terms of stone clearance rate ( $93 \%$ vs. $95 \%$ ), but a significantly lower rate of morbidity ( $6 \%$ vs. $11 \%$; OR $0.54,95 \% \mathrm{Cl} 0.31-$ $0.96 ; P=0.03)$, including post-ERCP pancreatitis $(0.6 \%$ vs. $4.4 \%$; OR $0.19,95 \% \mathrm{Cl} 0.06-0.67 ; P=0.01$ ) and length of hospital stay in the intraoperative ERCP group [202]. In addition, the Swedish GallRiks registry, comprising 12718 ERCP procedures, demonstrated a substantial $50 \%$ risk reduction in post-ERCP pancreatitis (3.6\% vs. $2.2 \%$; OR 0.5 , $95 \% \mathrm{Cl} 0.2-0.9 ; P=0.002$ ) when rendezvous cannulation was practiced [203].

Intraoperative rendezvous ERCP does however carry logistical problems related to the prolonged surgical time and the need to perform ERCP in an environment that is not adapted for endoscopy $[180,182,189,191,204]$. Failure to pass the guidewire along a narrow cystic duct or papilla is reported in about $8 \%$ of cases (Table 12s); if this happens, the endoscopist must rely on conventional cannulation techniques and their associated risks.

\subsection{Surgical treatment of CBDSs}

\section{RECOMMENDATION}

ESGE suggests that, in patients undergoing laparoscopic cholecystectomy, transcystic or transductal exploration of the common bile duct is a safe and effective technique for common bile duct stone clearance. The recommendation takes into account that management is dependent on local expertise and resources.

Weak recommendation, moderate quality evidence.

The surgical treatment of CBDSs can be performed during both laparoscopic and open cholecystectomy. It offers the valuable opportunity to definitively treat patients with combined cholecystolithiasis and choledocholithiasis in a one-stage procedure.

Several studies have compared laparoscopic bile duct exploration during laparoscopic cholecystectomy with pre- or postoperative ERCP and have demonstrated no significant differences in clinical outcomes [205-207]. However, one-stage procedures, such as laparoscopic CBD exploration or combined endo-laparoscopic approaches, usually result in a shorter hospital stay [208-217]. Moreover, a recent meta-analysis has demonstrated that the one-stage laparoscopic procedure has 
a higher success rate than the sequential endo-laparoscopic approach [218].

It is of note that the results of surgical treatment of CBDSs, which are generally excellent in published reports, usually originate from laparoscopic centers of excellence, and there are hardly any data on outcomes by less experienced surgeons. Moreover, there is a trend over the last decades that the use of endoscopic management is increasing and surgical trainees are not gaining adequate experience in CBD exploration [219].

\section{Special situations}

Acute cholangitis and ABP may complicate CBDSs, resulting in a more difficult therapeutic approach. Moreover, CBDSs may occur in special clinical settings, such as in pregnant women. The endoscopic management of ABP was the object of the ESGE Guideline on endoscopic treatment of necrotizing pancreatitis [220].

\subsection{Acute cholangitis}

The majority of patients with gallstone cholangitis have mildto-moderate disease that usually responds to antibiotic therapy. However, $15 \%-30 \%$ of patients have severe disease that needs to be handled with urgent biliary decompression [221].

Identification and stratification of cholangitis severity is fundamental to selecting the appropriate treatment.

\section{RECOMMENDATION}

ESGE recommends using the 2018 revision of the Tokyo Guidelines to classify the severity of acute cholangitis. Strong recommendation, low quality evidence.

The 2013 revision of the Tokyo Guidelines [221], recently confirmed by the 2018 revision [222], classifies acute cholangitis as:

- severe, dysfunction of at least one of the following systems: cardiovascular, neurological, respiratory, renal, hepatic, or hematological system (specific criteria are stated for each item)

- moderate, any of the following: white blood cell count $>12000$ or $<4000 / \mathrm{mm}^{3}$, fever $\geq 39{ }^{\circ} \mathrm{C}$, age $\geq 75$ years, total bilirubin $\geq 5 \mathrm{mg} / \mathrm{dL}$, or hypoalbuminemia

- mild, no criteria of moderate/severe cholangitis.

Companion mobile applications of the 2018 Tokyo Guidelines allow easy assessment of the severity of acute cholangitis (http://www.jshbps.jp/modules/en/index.php?content_id=47 Accessed 30 January 2019).

\subsection{Timing of ERCP in acute cholangitis}

\section{RECOMMENDATION}

ESGE recommends the following timing for biliary drainage, preferably endoscopic, in patients with acute cholangitis, classified according to the 2018 Tokyo Guidelines:

- severe, as soon as possible and within 12 hours for patients with septic shock

- moderate, within 48-72 hours

- mild, elective.

Strong recommendation, low quality evidence.

Twelve studies (18 206 patients), all retrospective, have analyzed the relationship between the timing of biliary drainage and different outcomes (Table 14s). An international study from 28 intensive care units published in 2016 included 260 patients with septic shock (defined as hypotension requiring vasopressors plus several other criteria); it found that waiting longer than 12 hours from the onset of shock to successful biliary drainage was associated with higher in-hospital mortality (OR $3.4,95 \% \mathrm{Cl} 1.12-10.31$ ) [223]. Overall, in-hospital mortality was $37 \%$ and median time to biliary drainage was 12 hours, with $10 \%$ of patients having drainage after 48 hours [223].

The other 11 studies were not restricted to patients with disease that was so severe [224-234]; they revealed, among the studies that analyzed the specific matter, that: mortality was associated with delayed ERCP in two of four studies $[223,233]$; organ failure (alone or as part of a composite index) was associated with delayed ERCP in three of five studies [226, 227,230]; length of hospital stay was associated with the timing of ERCP in seven of eight studies [225, 227, 229, 230, 232 -234]; hospitalization costs were higher when ERCP was delayed in both studies that analyzed that association [230, 233].

\section{RECOMMENDATION}

ESGE recommends other biliary drainage modalities (percutaneous, surgical) in patients with acute cholangitis due to common bile duct stones when ERCP is not feasible/successful within the recommended timeframes.

Strong recommendation, low quality evidence.

Failure of biliary drainage is a strong determinant of mortality, particularly in patients with severe cholangitis. For example, in the abovementioned study of patients with septic shock [223], 40 of 42 patients with failed biliary drainage (95.3\%) died as compared with 55 of 213 patients with successful biliary drainage $(25.8 \%)$. In that study, biliary drainage was achieved by ERCP, percutaneous transhepatic biliary drainage (PTBD), and surgery in 91, 90, and 34 patients, respectively. Similarly, in a study not restricted to patients with severe disease [225], three of six patients with failed biliary drainage $(50 \%)$ died as compared with two of 321 patients with successful biliary drainage $(0.6 \%)$. 


\subsection{Management of CBDSs in pregnant woman}

\section{RECOMMENDATION}

ESGE recommends that therapeutic ERCP is a safe and effective procedure in pregnant women, provided that it is performed by experienced endoscopists and the radiation exposure to the fetus is kept as low as possible. Strong recommendation, moderate quality of evidence.

According to six retrospective studies (144 patients), ERCP in pregnant women seems to be a relatively safe examination throughout the whole gestation [235-240]. ERCP should only be performed for therapeutic purposes as EUS and MRCP are highly accurate for the diagnosis of biliary obstruction. Furthermore, it should be performed by experienced endoscopists as radiation dose, as well as the overall complication rate, decreases with the experience of the endoscopist [241 - 244].

With respect to the potential harm related to $X$-rays, ERCP is best carried out during the second trimester of pregnancy; during the first trimester, the phase of organogenesis, the fetus is especially sensitive to radiation and, during the third trimester, there is a close topographic proximity of the growing fetus to the path of the X-rays.

Guidelines have usually recommended using as little radiation as reasonably achievable $[243,245]$. A threshold radiation dose is assumed for deterministic effects only (10 mGy), not for stochastic effects (cancer induction) [246]. Therefore, as many steps as possible should be taken to keep radiation exposure as low as possible. These are described in the ESGE Guideline on radiation protection in digestive endoscopy [243]. Non-radiation ERCP (NR-ERCP) has also been proposed; it uses various techniques such as aspiration of bile through the cannulation catheter to confirm biliary cannulation, ultrasound guidance, peroral cholangioscopy, or a two-stage approach consisting of biliary stenting followed by stone extraction after parturition. A systematic review summarized 22 case reports and retrospective studies that used NR-ERCP (180 patients in total) [247]. They concluded that pregnancy outcomes were not significantly affected by NR-ERCP, although whether the avoidance of radiation is beneficial for the baby remains unknown, but noted that NR-ERCP is technically demanding.

\section{Disclaimer}

The legal disclaimer for ESGE Guidelines [12] applies to the current Guideline.

\section{Acknowledgments}

The authors gratefully acknowledge Dr. Payal Saxena, AW Morrow Gastroenterology and Liver Center, Royal Prince Alfred Hospital, Sydney, Australia and Dr. Fauze Maluf-Filho, Endoscopy Unit of the Cancer Institute of São Paulo - ICESP, Department of Gastroenterology of the University of São Paulo, Brazil for their valuable contribution in reviewing this guideline.
Competing interests

A. Anderloni has provided consultancy to Boston Scientific (20162018) and Olympus (2018). M. Barthet's department received a research grant (2016-2018). D. Domagk's department has received workshop, consultancy, and speaker's fees from Hitachi (2016 to present), and speaker's fees and symposia support from Dr. Falk Foundation and Olympus (both 2015 to present). I. Hritz has provided consultancy and training for Olympus (2017 to present) and consultancy to Pentax Medical (2018 to present). G. Paspatis has received sponsorship for invited speeches from Boston Scientific (20142018). T. Ponchon has been on the advisory board of Olympus (2018) and his department has received clinical research funding from Fujifilm (2018). J. E. van Hooft received lecture fees from Medtronics (2014-2015) and provided consultancy to Boston Scientific (2014-2016), her department has received research grants from Cook Medical (2014-2018) and Abbott (2014-2017). E. J. Williams was chair of the British Society of Gastroenterology writing group for guidelines on common bile duct stones (2014-2017). L. Aabakken, P. Ah-Soune, M. Arvanitakis, J.-M. Dumonceau, J.-F. Gigot, G. Karamanolis, A. Laghi, G. Manes, A. Mariani, K. Paraskeva, J. Pohl, F. Swahn, R. ter Steege, A. Tringali, and A. Vezakis have no competing interests.

References

[1] Everhart JE, Khare M, Hill M et al. Prevalence and ethnic differences in gallbladder disease in the United States. Gastroenterology 1999; 117: $632-639$

[2] Shaffer EA. Gallstone disease: Epidemiology of gallbladder stone disease. Best Pract Res Clin Gastroenterol 2006; 20: 981 - 996

[3] Tazuma S. Gallstone disease: Epidemiology, pathogenesis, and classification of biliary stones (common bile duct and intrahepatic). Best Pract Res Clin Gastroenterol 2006; 20: 1075-1083

[4] Barbara L, Sama C, Morselli Labate AM et al. A population study on the prevalence of gallstone disease: the Sirmione Study. Hepatology 1987; 7: $913-917$

[5] Halldestam I, Enell EL, Kullman E et al. Development of symptoms and complications in individuals with asymptomatic gallstones. Br J Surg 2004; 91: 734-738

[6] Fein M, Bueter M, Sailer M et al. Effect of cholecystectomy on gastric and esophageal bile reflux in patients with upper gastrointestinal symptoms. Dig Dis Sci 2008; 53: $1186-1191$

[7] Gracie WA, Ransohoff DF. The natural history of silent gallstones: the innocent gallstone is not a myth. NEJM 1982; 307: 798-800

[8] McSherry CK, Ferstenberg H, Calhoun WF et al. The natural history of diagnosed gallstone disease in symptomatic and asymptomatic patients. Ann Surg 1985; 202: 59-63

[9] Shabanzadeh DM, Sorensen LT, Jorgensen T. A prediction rule for risk stratification of incidentally discovered gallstones: results from a large cohort study. Gastroenterology 2016; 150: 156-167

[10] Ransohoff DF, Gracie WA, Wolfenson LB et al. Prophylactic cholecystectomy or expectant management for silent gallstones. A decision analysis to assess survival. Ann Intern Med 1983; 99: 199-204

[11] Friedman GD. Natural history of asymptomatic and symptomatic gallstones. Am J Surg 1993; 165: 399-404

[12] Dumonceau JM, Hassan C, Riphaus A et al. European Society of Gastrointestinal Endoscopy (ESGE) Guideline Development Policy. Endoscopy 2012; 44: 626-629

[13] Shabanzadeh DM, Sorensen LT, Jorgensen T. Determinants for gallstone formation - a new data cohort study and a systematic review with meta-analysis. Scand J Gastroenterol 2016; 51: 1239-1248 
[14] Moller M, Gustafsson U, Rasmussen F et al. Natural course vs interventions to clear common bile duct stones: data from the Swedish Registry for Gallstone Surgery and Endoscopic Retrograde Cholangiopancreatography (GallRiks). JAMA Surg 2014; 149: 1008-1013

[15] Collins C, Maguire D, Ireland A et al. A prospective study of common bile duct calculi in patients undergoing laparoscopic cholecystectomy: natural history of choledocholithiasis revisited. Ann Surg 2004; 239: $28-33$

[16] Murison MS, Gartell PC, McGinn FP. Does selective peroperative cholangiography result in missed common bile duct stones? J R Coll Surg Edinb 1993; 38: $220-224$

[17] Csendes A, Burdiles P, Diaz JC et al. Prevalence of common bile duct stones according to the increasing number of risk factors present. A prospective study employing routinely intraoperative cholangiography in 477 cases. Hepatogastroenterology 1998; 45: 1415-1421

[18] Ko CW, Lee SP. Epidemiology and natural history of common bile duct stones and prediction of disease. Gastrointest Endosc 2002; 56: S165-S169

[19] Soper NJ, Dunnegan DL. Routine versus selective intra-operative cholangiography during laparoscopic cholecystectomy. World J Surg 1992; 16: $1133-1140$

[20] Nies C, Bauknecht F, Groth C et al. Intraoperative cholangiography as a routine method? A prospective, controlled, randomized study. Chirurg 1997; 68: 892-897

[21] Khan OA, Balaji S, Branagan G et al. Randomized clinical trial of routine on-table cholangiography during laparoscopic cholecystectomy. Br J Surg 2011; 98: $362-367$

[22] Hauer-Jensen M, Karesen R, Nygaard K et al. Prospective randomized study of routine intraoperative cholangiography during open cholecystectomy: long-term follow-up and multivariate analysis of predictors of choledocholithiasis. Surgery 1993; 113: 318-323

[23] Frossard JL, Hadengue A, Amouyal G et al. Choledocholithiasis: a prospective study of spontaneous common bile duct stone migration. Gastrointest Endosc 2000; 51: 175-179

[24] Cox MR, Budge JP, Eslick GD. Timing and nature of presentation of unsuspected retained common bile duct stones after laparoscopic cholecystectomy: a retrospective study. Surg Endosc 2015; 29: $2033-2038$

[25] Kim SB, Kim KH, Kim TN. Comparison of outcomes and complications of endoscopic common bile duct stone removal between asymptomatic and symptomatic patients. Dig Dis Sci 2016; 61: 1172-1177

[26] Gurusamy KS, Giljaca V, Takwoingi Y et al. Ultrasound versus liver function tests for diagnosis of common bile duct stones. Cochrane Database Syst Rev 2015: CD011548

[27] Anderson SW, Rho E, Soto JA. Detection of biliary duct narrowing and choledocholithiasis: accuracy of portal venous phase multidetector CT. Radiology 2008; 247: 418-427

[28] Kim CW, Chang JH, Lim YS et al. Common bile duct stones on multidetector computed tomography: attenuation patterns and detectability. World J Gastroenterol 2013; 19: 1788-1796

[29] Tseng CW, Chen CC, Chen TS et al. Can computed tomography with coronal reconstruction improve the diagnosis of choledocholithiasis? J Gastroenterol Hepatol 2008; 23: 1586-1589

[30] Tse F, Barkun JS, Barkun AN. The elective evaluation of patients with suspected choledocholithiasis undergoing laparoscopic cholecystectomy. Gastrointest Endosc 2004; 60: 437-448

[31] Barkun AN, Barkun JS, Fried GM et al. Useful predictors of bile duct stones in patients undergoing laparoscopic cholecystectomy. McGill Gallstone Treatment Group. Ann Surg 1994; 220: 32 - 39

[32] Onken JE, Brazer SR, Eisen GM et al. Predicting the presence of choledocholithiasis in patients with symptomatic cholelithiasis. Am J Gastroenterol 1996; 91: $762-767$
[33] Prat F, Meduri B, Ducot B et al. Prediction of common bile duct stones by noninvasive tests. Ann Surg 1999; 229: $362-368$

[34] Abboud PA, Malet PF, Berlin JA et al. Predictors of common bile duct stones prior to cholecystectomy: a meta-analysis. Gastrointest Endosc 1996; 44: $450-455$

[35] Wilcox CM, Kim H, Trevino J et al. Prevalence of normal liver tests in patients with choledocholithiasis undergoing endoscopic retrograde cholangiopancreatography. Digestion 2014; 89: 232-238

[36] Qiu Y, Yang Z, Li Z et al. Is preoperative MRCP necessary for patients with gallstones? An analysis of the factors related to missed diagnosis of choledocholithiasis by preoperative ultrasound. BMC Gastroenterol 2015; 15: 158

[37] Meeralam Y, Al-Shammari K, Yaghoobi M. Diagnostic accuracy of EUS compared with MRCP in detecting choledocholithiasis: a meta-analysis of diagnostic test accuracy in head-to-head studies. Gastrointest Endosc 2017; 86: 986 - 993

[38] Giljaca V, Gurusamy KS, Takwoingi Y et al. Endoscopic ultrasound versus magnetic resonance cholangiopancreatography for common bile duct stones. Cochrane Database Syst Rev 2015: CD011549

[39] Sonnenberg A, Enestvedt BK, Bakis G. Management of suspected choledocholithiasis: a decision analysis for choosing the optimal imaging modality. Dig Dis Sci 2016; 61: 603-609

[40] Kullman E, Borch K, Lindstrom E et al. Bacteremia following diagnostic and therapeutic ERCP. Gastrointest Endosc 1992; 38: $444-449$

[41] Deviere J, Motte S, Dumonceau JM et al. Septicemia after endoscopic retrograde cholangiopancreatography. Endoscopy 1990; 22: 72 - 75

[42] Sauter G, Grabein B, Huber G et al. Antibiotic prophylaxis of infectious complications with endoscopic retrograde cholangiopancreatography. A randomized controlled study. Endoscopy 1990; 22: 164-167

[43] Lorenz R, Lehn N, Born P et al. Antibiotic prophylaxis using cefuroxime in bile duct endoscopy. Dtsch Med Wochenschr 1996; 121: 223-230

[44] van den Hazel SJ, Speelman P, Dankert J et al. Piperacillin to prevent cholangitis after endoscopic retrograde cholangiopancreatography. A randomized, controlled trial. Ann Intern Med 1996; 125: 442 - 447

[45] Niederau C, Pohlmann U, Lubke $\mathrm{H}$ et al. Prophylactic antibiotic treatment in therapeutic or complicated diagnostic ERCP: results of a randomized controlled clinical study. Gastrointest Endosc 1994; 40: $533-537$

[46] Byl B, Deviere J, Struelens M] et al. Antibiotic prophylaxis for infectious complications after therapeutic endoscopic retrograde cholangiopancreatography: a randomized, double-blind, placebo-controlled study. Clin Infect Dis 1995; 20: 1236-1240

[47] Raty S, Sand J, Pulkkinen M et al. Post-ERCP pancreatitis: reduction by routine antibiotics. J Gastrointest Surg 2001; 5: 339-345 ; discussion 345

[48] Harris A, Chan AC, Torres-Viera C et al. Meta-analysis of antibiotic prophylaxis in endoscopic retrograde cholangiopancreatography (ERCP). Endoscopy 1999; 31: 718-724

[49] Bai Y, Gao F, Gao J et al. Prophylactic antibiotics cannot prevent endoscopic retrograde cholangiopancreatography-induced cholangitis: a meta-analysis. Pancreas 2009; 38: 126-130

[50] Brand M, Bizos D, O'Farrell P Jr. Antibiotic prophylaxis for patients undergoing elective endoscopic retrograde cholangiopancreatography. Cochrane Database Syst Rev 2010: CD007345

[51] Cotton PB, Connor P, Rawls E et al. Infection after ERCP, and antibiotic prophylaxis: a sequential quality-improvement approach over 11 years. Gastrointest Endosc 2008; 67: $471-475$

[52] Ellis RD, Jenkins AP, Thompson RP et al. Clearance of refractory bile duct stones with extracorporeal shockwave lithotripsy. Gut 2000; 47 : $728-731$

[53] Sackmann M, Holl J, Sauter GH et al. Extracorporeal shock wave lithotripsy for clearance of bile duct stones resistant to endoscopic extraction. Gastrointest Endosc 2001; 53: 27-32 
[54] Othman MO, Guerrero R, Elhanafi S et al. A prospective study of the risk of bacteremia in directed cholangioscopic examination of the common bile duct. Gastrointest Endosc 2016; 83: 151 - 157

[55] Testoni PA, Mariani A, Aabakken L et al. Papillary cannulation and sphincterotomy techniques at ERCP: European Society of Gastrointestinal Endoscopy (ESGE) Clinical Guideline. Endoscopy 2016; 48: $657-683$

[56] Dumonceau JM, Andriulli A, Elmunzer BJ et al. Prophylaxis of postERCP pancreatitis: European Society of Gastrointestinal Endoscopy (ESGE) Guideline - updated June 2014. Endoscopy 2014; 46: 799-815

[57] Carr-Locke DL. Difficult bile-duct stones: cut, dilate, or both? Gastrointest Endosc 2008; 67: 1053 - 1055

[58] Park CH, Jung JH, Nam E et al. Comparative efficacy of various endoscopic techniques for the treatment of common bile duct stones: a network meta-analysis. Gastrointest Endosc 2018; 87: 43 - 57 e10

[59] Weinberg BM, Shindy W, Lo S. Endoscopic balloon sphincter dilation (sphincteroplasty) versus sphincterotomy for common bile duct stones. Cochrane Database Syst Rev 2006: CD004890

[60] Ando T, Tsuyuguchi T, Okugawa T et al. Risk factors for recurrent bile duct stones after endoscopic papillotomy. Gut 2003; 52: 116-121

[61] Zhao WC, Chen BD, Yang A et al. Small endoscopic biliary sphincterotomy facilitates long-term recurrence of common bile duct stones. Int J Clin Exp Med 2017; 10: 3644-3652

[62] Ishiwatari $\mathrm{H}$, Kawakami H, Hisai $\mathrm{H}$ et al. Balloon catheter versus basket catheter for endoscopic bile duct stone extraction: a multicenter randomized trial. Endoscopy 2016; 48: 350-357

[63] Ozawa N, Yasuda I, Doi S et al. Prospective randomized study of endoscopic biliary stone extraction using either a basket or a balloon catheter: the BasketBall study. J Gastroenterol 2017; 52: 623-630

[64] ASGE Technology Committee, Adler DG, Conway JD et al. Biliary and pancreatic stone extraction devices. Gastrointest Endosc 2009; 70: 603-609

[65] Sivak MV Jr. Endoscopic management of bile duct stones. Am J Surg 1989; 158: $228-240$

[66] Katsinelos P, Kountouras J, Paroutoglou G et al. Combination of endoprostheses and oral ursodeoxycholic acid or placebo in the treatment of difficult to extract common bile duct stones. Dig Liver Dis 2008; 40: $453-459$

[67] Han J, Moon JH, Koo HC et al. Effect of biliary stenting combined with ursodeoxycholic acid and terpene treatment on retained common bile duct stones in elderly patients: a multicenter study. Am J Gastroenterol 2009; 104: 2418-2421

[68] Lee TH, Han JH, Kim H] et al. Is the addition of choleretic agents in multiple double-pigtail biliary stents effective for difficult common bile duct stones in elderly patients? A prospective, multicenter study. Gastrointest Endosc 2011; 74: 96-102

[69] Chan AC, Ng EK, Chung SC et al. Common bile duct stones become smaller after endoscopic biliary stenting. Endoscopy 1998; 30: $356-$ 359

[70] Katsinelos P, Galanis I, Pilpilidis I et al. The effect of indwelling endoprosthesis on stone size or fragmentation after long-term treatment with biliary stenting for large stones. Surg Endosc 2003; 17: 1552 1555

[71] Horiuchi A, Nakayama Y, Kajiyama M et al. Biliary stenting in the management of large or multiple common bile duct stones. Gastrointest Endosc 2010; 71: 1200 - 1203 e1202

[72] Hong WD, Zhu QH, Huang QK. Endoscopic sphincterotomy plus endoprostheses in the treatment of large or multiple common bile duct stones. Dig Endosc 2011; 23: 240-243

[73] Fan Z, Hawes R, Lawrence $C$ et al. Analysis of plastic stents in the treatment of large common bile duct stones in 45 patients. Dig Endosc 2011; 23: 86-90
[74] Yang J, Peng JY, Chen W. Endoscopic biliary stenting for irretrievable common bile duct stones: Indications, advantages, disadvantages, and follow-up results. Surgeon 2012; 10: $211-217$

[75] Maxton DG, Tweedle DE, Martin DF. Retained common bile duct stones after endoscopic sphincterotomy: temporary and longterm treatment with biliary stenting. Gut 1995; 36: $446-449$

[76] Jain SK, Stein R, Bhuva M et al. Pigtail stents: an alternative in the treatment of difficult bile duct stones. Gastrointest Endosc 2000; 52: $490-493$

[77] Ye X, Huai J, Sun X. Effectiveness and safety of biliary stenting in the management of difficult common bile duct stones in elderly patients. Turk J Gastroenterol 2016; 27: 30 - 36

[78] Minami A, Fujita R. A new technique for removal of bile duct stones with an expandable metallic stent. Gastrointest Endosc 2003; 57: $945-948$

[79] Cerefice M, Sauer B, Javaid M et al. Complex biliary stones: treatment with removable self-expandable metal stents: a new approach (with videos). Gastrointest Endosc 2011; 74: 520 - 526

[80] Hartery K, Lee CS, Doherty GA et al. Covered self-expanding metal stents for the management of common bile duct stones. Gastrointest Endosc 2017; 85: $181-186$

[81] Di Giorgio P, Manes G, Grimaldi E et al. Endoscopic plastic stenting for bile duct stones: stent changing on demand or every 3 months. A prospective comparison study. Endoscopy 2013; 45: 1014-1017

[82] Day LW, Lin L, Somsouk M. Adverse events in older patients undergoing ERCP: a systematic review and meta-analysis. Endosc Int Open 2014; 2: E28 - E36

[83] Bergman JJ, Rauws EA, Tijssen JG et al. Biliary endoprostheses in elderly patients with endoscopically irretrievable common bile duct stones: report on 117 patients. Gastrointest Endosc 1995; 42: 195 201

[84] Chopra KB, Peters RA, O'Toole PA et al. Randomised study of endoscopic biliary endoprosthesis versus duct clearance for bileduct stones in high-risk patients. Lancet 1996; 348: 791 - 793

[85] De Palma GD, Catanzano C. Stenting or surgery for treatment of irretrievable common bile duct calculi in elderly patients? Am J Surg 1999; 178: $390-393$

[86] De Palma GD, Galloro G, Siciliano S et al. Endoscopic stenting for definitive treatment of irretrievable common bile duct calculi. A longterm follow-up study of 49 patients. Hepatogastroenterology 2001; 48: $56-58$

[87] Hui CK, Lai KC, Ng M et al. Retained common bile duct stones: a comparison between biliary stenting and complete clearance of stones by electrohydraulic lithotripsy. Aliment Pharmacol Ther 2003; 17: $289-296$

[88] Pisello F, Geraci G, Li Volsi F et al. Permanent stenting in "unextractable" common bile duct stones in high risk patients. A prospective randomized study comparing two different stents. Langenbecks Arch Surg 2008; 393: $857-863$

[89] Kim DI, Kim MH, Lee SK et al. Risk factors for recurrence of primary bile duct stones after endoscopic biliary sphincterotomy. Gastrointest Endosc 2001; 54: $42-48$

[90] Keizman D, Ish Shalom M, Konikoff FM. Recurrent symptomatic common bile duct stones after endoscopic stone extraction in elderly patients. Gastrointest Endosc 2006; 64: 60-65

[91] Cheon YK, Lehman GA. Identification of risk factors for stone recurrence after endoscopic treatment of bile duct stones. Eur J Gastroenterol Hepatol 2006; 18: $461-464$

[92] Swobodnik W, Janowitz P, Kratzer W et al. Preventing the recurrence of common bile duct calculi following endoscopic papillotomy with ursodeoxycholic acid. Z Gastroenterol 1990; 28: 621-625 
[93] Yamamoto R, Tazuma S, Kanno K et al. Ursodeoxycholic acid after bile duct stone removal and risk factors for recurrence: a randomized trial. J Hepatobiliary Pancreat Sci 2016; 23: 132 - 136

[94] Trikudanathan G, Navaneethan U, Parsi MA. Endoscopic management of difficult common bile duct stones. World J Gastroenterol 2013; 19: $165-173$

[95] Kim HJ, Choi HS, Park JH et al. Factors influencing the technical difficulty of endoscopic clearance of bile duct stones. Gastrointest Endosc 2007; 66: $1154-1160$

[96] McHenry L, Lehman G. Difficult bile duct stones. Curr Treat Options Gastroenterol 2006; 9: 123-132

[97] Ersoz G, Tekesin O, Ozutemiz AO et al. Biliary sphincterotomy plus dilation with a large balloon for bile duct stones that are difficult to extract. Gastrointest Endosc 2003; 57: 156 - 159

[98] Stefanidis G, Viazis N, Pleskow D et al. Large balloon dilation vs. mechanical lithotripsy for the management of large bile duct stones: a prospective randomized study. Am J Gastroenterol 2011; 106: 278 285

[99] Heo JH, Kang DH, Jung $\mathrm{H}$ J et al. Endoscopic sphincterotomy plus large-balloon dilation versus endoscopic sphincterotomy for removal of bile-duct stones. Gastrointest Endosc 2007; 66: 720 - 726; quiz 768, 771

[100] Teoh AY, Cheung FK, Hu B et al. Randomized trial of endoscopic sphincterotomy with balloon dilation versus endoscopic sphincterotomy alone for removal of bile duct stones. Gastroenterology 2013; 144: 341 - 345 e341

[101] Kim HG, Cheon YK, Cho YD et al. Small sphincterotomy combined with endoscopic papillary large balloon dilation versus sphincterotomy. World J Gastroenterol 2009; 15: 4298-4304

[102] Li G, Pang Q, Zhang X et al. Dilation-assisted stone extraction: an alternative method for removal of common bile duct stones. Dig Dis Sci 2014; 59: $857-864$

[103] Jun Bo Q, Li Hua X, Tian Min C et al. Small endoscopic sphincterotomy plus large-balloon dilation for removal of large common bile duct stones during ERCP. Pak J Med Sci 2013; 29: 907 - 912

[104] Karsenti D, Coron E, Vanbiervliet G et al. Complete endoscopic sphincterotomy with vs. without large-balloon dilation for the removal of large bile duct stones: randomized multicenter study. Endoscopy 2017; 49: 968 - 976

[105] Feng Y, Zhu H, Chen X et al. Comparison of endoscopic papillary large balloon dilation and endoscopic sphincterotomy for retrieval of choledocholithiasis: a meta-analysis of randomized controlled trials. J Gastroenterol 2012; 47: 655-663

[106] Madhoun MF, Wani S, Hong S et al. Endoscopic papillary large balloon dilation reduces the need for mechanical lithotripsy in patients with large bile duct stones: a systematic review and meta-analysis. Diagn Ther Endosc 2014; 2014: 309618

[107] Yang XM, Hu B. Endoscopic sphincterotomy plus large-balloon dilation vs endoscopic sphincterotomy for choledocholithiasis: a metaanalysis. World J Gastroenterol 2013; 19: 9453 - 9460

[108] Jin PP, Cheng JF, Liu D et al. Endoscopic papillary large balloon dilation vs endoscopic sphincterotomy for retrieval of common bile duct stones: a meta-analysis. World J Gastroenterol 2014; 20: 5548 5556

[109] Liu Y, Su P, Lin Y et al. Endoscopic sphincterotomy plus balloon dilation versus endoscopic sphincterotomy for choledocholithiasis: A meta-analysis. J Gastroenterol Hepatol 2013; 28: 937 - 945

[110] Kim JH, Yang MJ, Hwang JC et al. Endoscopic papillary large balloon dilation for the removal of bile duct stones. World J Gastroenterol 2013; 19: $8580-8594$

[111] Kim TH, Kim JH, Seo DW et al. International consensus guidelines for endoscopic papillary large-balloon dilation. Gastrointest Endosc 2016; 83: $37-47$
[112] Kim KO, Kim TN, Lee SH. Endoscopic papillary large balloon dilation for the treatment of recurrent bile duct stones in patients with prior sphincterotomy. J Gastroenterol 2010; 45: 1283-1288

[113] Kurita A, Maguchi H, Takahashi K et al. Large balloon dilation for the treatment of recurrent bile duct stones in patients with previous endoscopic sphincterotomy: preliminary results. Scand J Gastroenterol 2010; 45: $1242-1247$

[114] Yoon HG, Moon JH, Choi HJ et al. Endoscopic papillary large balloon dilation for the management of recurrent difficult bile duct stones after previous endoscopic sphincterotomy. Dig Endosc 2014; 26: $259-263$

[115] Paspatis GA, Paraskeva K, Vardas E et al. Long-term recurrence of bile duct stones after endoscopic papillary large balloon dilation with sphincterotomy: 4-year extended follow-up of a randomized trial. Surg Endosc 2017; 31: 650-655

[116] Maydeo A, Bhandari S. Balloon sphincteroplasty for removing difficult bile duct stones. Endoscopy 2007; 39: 958-961

[117] Misra SP, Dwivedi M. Large-diameter balloon dilation after endoscopic sphincterotomy for removal of difficult bile duct stones. Endoscopy 2008; 40: 209-213

[118] Attasaranya S, Cheon YK, Vittal H et al. Large-diameter biliary orifice balloon dilation to aid in endoscopic bile duct stone removal: a multicenter series. Gastrointest Endosc 2008; 67: 1046-1052

[119] Draganov PV, Evans W, Fazel A et al. Large size balloon dilation of the ampulla after biliary sphincterotomy can facilitate endoscopic extraction of difficult bile duct stones. J Clin Gastroenterol 2009; 43 : $782-786$

[120] Park S], Kim JH, Hwang JC et al. Factors predictive of adverse events following endoscopic papillary large balloon dilation: results from a multicenter series. Dig Dis Sci 2013; 58: 1100 -1109

[121] Paspatis GA, Konstantinidis K, Tribonias G et al. Sixty- versus thirtyseconds papillary balloon dilation after sphincterotomy for the treatment of large bile duct stones: a randomized controlled trial. Dig Liver Dis 2013; 45: 301 - 304

[122] Minami A, Hirose S, Nomoto T et al. Small sphincterotomy combined with papillary dilation with large balloon permits retrieval of large stones without mechanical lithotripsy. World J Gastroenterol 2007; 13: $2179-2182$

[123] Kim TH, Oh HJ, Lee JY et al. Can a small endoscopic sphincterotomy plus a large-balloon dilation reduce the use of mechanical lithotripsy in patients with large bile duct stones? Surg Endosc 2011; 25: $3330-3337$

[124] Youn YH, Lim HC, Jahng JH et al. The increase in balloon size to over $15 \mathrm{~mm}$ does not affect the development of pancreatitis after endoscopic papillary large balloon dilatation for bile duct stone removal. Dig Dis Sci 2011; 56: $1572-1577$

[125] Rebelo A, Ribeiro PM, Correia AP et al. Endoscopic papillary large balloon dilation after limited sphincterotomy for difficult biliary stones. World J Gastrointest Endosc 2012; 4: 180-184

[126] Rosa B, Moutinho Ribeiro P, Rebelo A et al. Endoscopic papillary balloon dilation after sphincterotomy for difficult choledocholithiasis: A case-controlled study. World J Gastrointest Endosc 2013; 5: 211 218

[127] Yang XM, Hu B, Pan YM et al. Endoscopic papillary large-balloon dilation following limited sphincterotomy for the removal of refractory bile duct stones: experience of 169 cases in a single Chinese center. J Dig Dis 2013; 14: 125-131

[128] Rouquette O, Bommelaer G, Abergel A et al. Large balloon dilation post endoscopic sphincterotomy in removal of difficult common bile duct stones: a literature review. World J Gastroenterol 2014; 20 : $7760-7766$

[129] Garg PK, Tandon RK, Ahuja V et al. Predictors of unsuccessful mechanical lithotripsy and endoscopic clearance of large bile duct stones. Gastrointest Endosc 2004; 59: 601 - 605 
[130] Cipolletta L, Costamagna G, Bianco MA et al. Endoscopic mechanical lithotripsy of difficult common bile duct stones. Br J Surg 1997; 84: $1407-1409$

[131] Chung SC, Leung JW, Leong HT et al. Mechanical lithotripsy of large common bile duct stones using a basket. Br J Surg 1991; 78: 1448 1450

[132] Lee SH, Park JK, Yoon WJ et al. How to predict the outcome of endoscopic mechanical lithotripsy in patients with difficult bile duct stones? Scand J Gastroenterol 2007; 42: 1006-1010

[133] Chang WH, Chu CH, Wang TE et al. Outcome of simple use of mechanical lithotripsy of difficult common bile duct stones. World J Gastroenterol 2005; 11: 593-596

[134] Hintze RE, Adler A, Veltzke W. Outcome of mechanical lithotripsy of bile duct stones in an unselected series of 704 patients. Hepatogastroenterology 1996; 43: 473-476

[135] Thomas M, Howell DA, Carr-Locke D et al. Mechanical lithotripsy of pancreatic and biliary stones: complications and available treatment options collected from expert centers. Am J Gastroenterol 2007; 102: $1896-1902$

[136] Tringali A, Lemmers A, Meves V et al. Intraductal biliopancreatic imaging: European Society of Gastrointestinal Endoscopy (ESGE) technology review. Endoscopy 2015; 47: 739-753

[137] Korrapati P, Ciolino J, Wani S et al. The efficacy of peroral cholangioscopy for difficult bile duct stones and indeterminate strictures: a systematic review and meta-analysis. Endosc Int Open 2016; 4: E263-E275

[138] Farrell J], Bounds BC, Al-Shalabi S et al. Single-operator duodenoscope-assisted cholangioscopy is an effective alternative in the management of choledocholithiasis not removed by conventional methods, including mechanical lithotripsy. Endoscopy 2005; 37: $542-547$

[139] Chen YK, Parsi MA, Binmoeller KF et al. Single-operator cholangioscopy in patients requiring evaluation of bile duct disease or therapy of biliary stones (with videos). Gastrointest Endosc 2011; 74: 805814

[140] Maydeo A, Kwek BE, Bhandari S et al. Single-operator cholangioscopy-guided laser lithotripsy in patients with difficult biliary and pancreatic ductal stones (with videos). Gastrointest Endosc 2011; 74: $1308-1314$

[141] Patel SN, Rosenkranz L, Hooks B et al. Holmium-yttrium aluminum garnet laser lithotripsy in the treatment of biliary calculi using single-operator cholangioscopy: a multicenter experience (with video). Gastrointest Endosc 2014; 79: 344 - 348

[142] Buxbaum J, Sahakian A, Ko C et al. Randomized trial of cholangioscopy-guided laser lithotripsy versus conventional therapy for large bile duct stones (with videos). Gastrointest Endosc 2018; 87: 1050 1060

[143] Williams EJ, Green J, Beckingham I et al. Guidelines on the management of common bile duct stones (CBDS). Gut 2008; 57: $1004-$ 1021

[144] Sauerbruch T, Stern M. Fragmentation of bile duct stones by extracorporeal shock waves. A new approach to biliary calculi after failure of routine endoscopic measures. Gastroenterology 1989; 96: 146 152

[145] Adamek HE, Maier M, Jakobs R et al. Management of retained bile duct stones: a prospective open trial comparing extracorporeal and intracorporeal lithotripsy. Gastrointest Endosc 1996; 44: 40 - 47

[146] Neuhaus H, Zillinger C, Born P et al. Randomized study of intracorporeal laser lithotripsy versus extracorporeal shock-wave lithotripsy for difficult bile duct stones. Gastrointest Endosc 1998; 47: $327-334$

[147] Meyenberger C, Meierhofer U, Michel-Harder C et al. Long-term follow-up after treatment of common bile duct stones by extracorporeal shock-wave lithotripsy. Endoscopy 1996; 28: 411-417
[148] Bland KI, Jones RS, Maher JW et al. Extracorporeal shock-wave lithotripsy of bile duct calculi. An interim report of the Dornier U.S. Bile Duct Lithotripsy Prospective Study. Ann Surg 1989; 209: 743 - 753; discussion 753-745

[149] Nicholson DA, Martin DF, Tweedle DE et al. Management of common bile duct stones using a second-generation extracorporeal shockwave lithotriptor. Br J Surg 1992; 79: 811 -814

[150] Cecinato P, Fuccio L, Azzaroli F et al. Extracorporeal shock wave lithotripsy for difficult common bile duct stones: a comparison between 2 different lithotripters in a large cohort of patients. Gastrointest Endosc 2015; 81: 402 - 409

[151] Jakobs R, Adamek HE, Maier M et al. Fluoroscopically guided laser lithotripsy versus extracorporeal shock wave lithotripsy for retained bile duct stones: a prospective randomised study. Gut 1997; 40: $678-682$

[152] Karakayali F, Sevmis S, Ayvaz I et al. Acute necrotizing pancreatitis as a rare complication of extracorporeal shock wave lithotripsy. Int J Urol 2006; 13: 613-615

[153] Leifsson BG, Borgstrom A, Ahlgren G. Splenic rupture following ESWL for a pancreatic duct calculus. Dig Surg 2001; 18: 229-230

[154] McAlister VC, Davenport E, Renouf E. Cholecystectomy deferral in patients with endoscopic sphincterotomy. Cochrane Database Syst Rev 2007: CD006233

[155] Boerma D, Rauws EA, Keulemans YC et al. Wait-and-see policy or laparoscopic cholecystectomy after endoscopic sphincterotomy for bile-duct stones: a randomised trial. Lancet 2002; 360: 761 - 765

[156] Hammarstrom LE, Holmin T, Stridbeck H et al. Long-term follow-up of a prospective randomized study of endoscopic versus surgical treatment of bile duct calculi in patients with gallbladder in situ. $\mathrm{Br}$ J Surg 1995; 82: $1516-1521$

[157] Lau JY, Leow CK, Fung TM et al. Cholecystectomy or gallbladder in situ after endoscopic sphincterotomy and bile duct stone removal in Chinese patients. Gastroenterology 2006; 130: 96-103

[158] Suc B, Escat J, Cherqui D et al. Surgery vs endoscopy as primary treatment in symptomatic patients with suspected common bile duct stones: a multicenter randomized trial. French Associations for Surgical Research. Arch Surg 1998; 133: $702-708$

[159] Targarona EM, Ayuso RM, Bordas JM et al. Randomised trial of endoscopic sphincterotomy with gallbladder left in situ versus open surgery for common bileduct calculi in high-risk patients. Lancet 1996; 347: 926 - 929

[160] Reinders JS, Gouma DJ, Heisterkamp J et al. Laparoscopic cholecystectomy is more difficult after a previous endoscopic retrograde cholangiography. HPB (Oxford) 2013; 15: $230-234$

[161] Sarli L, lusco DR, Roncoroni L. Preoperative endoscopic sphincterotomy and laparoscopic cholecystectomy for the management of cholecystocholedocholithiasis: 10-year experience. World J Surg 2003; $27: 180-186$

[162] Reinders JS, Goud A, Timmer R et al. Early laparoscopic cholecystectomy improves outcomes after endoscopic sphincterotomy for choledochocystolithiasis. Gastroenterology 2010; 138: 2315-2320

[163] de Vries A, Donkervoort SC, van Geloven AA et al. Conversion rate of laparoscopic cholecystectomy after endoscopic retrograde cholangiography in the treatment of choledocholithiasis: does the time interval matter? Surg Endosc 2005; 19: 996 - 1001

[164] Schiphorst AH, Besselink MG, Boerma D et al. Timing of cholecystectomy after endoscopic sphincterotomy for common bile duct stones. Surg Endosc 2008; 22: 2046-2050

[165] Hamy A, Hennekinne S, Pessaux P et al. Endoscopic sphincterotomy prior to laparoscopic cholecystectomy for the treatment of cholelithiasis. Surg Endosc 2003; 17: 872 -875

[166] Heo J, Jung MK, Cho CM. Should prophylactic cholecystectomy be performed in patients with concomitant gallstones after endoscopic 
sphincterotomy for bile duct stones? Surg Endosc 2015; 29: 1574 1579

[167] Zargar SA, Mushtaq M, Beg MA et al. Wait-and-see policy versus cholecystectomy after endoscopic sphincterotomy for bile-duct stones in high-risk patients with co-existing gallbladder stones: a prospective randomised trial. Arab J Gastroenterol 2014; 15: 24 - 26

[168] Donkervoort SC, van Ruler O, Dijksman LM et al. Identification of risk factors for an unfavorable laparoscopic cholecystectomy course after endoscopic retrograde cholangiography in the treatment of choledocholithiasis. Surg Endosc 2010; 24: 798-804

[169] Aboulian A, Chan T, Yaghoubian A et al. Early cholecystectomy safely decreases hospital stay in patients with mild gallstone pancreatitis: a randomized prospective study. Ann Surg 2010; 251: 615-619

[170] da Costa DW, Bouwense SA, Schepers NJ et al. Same-admission versus interval cholecystectomy for mild gallstone pancreatitis (PONCHO): a multicentre randomised controlled trial. Lancet 2015; 386: $1261-1268$

[171] van Baal MC, Besselink MG, Bakker OJ et al. Timing of cholecystectomy after mild biliary pancreatitis: a systematic review. Ann Surg 2012; 255: $860-866$

[172] Nealon WH, Bawduniak J, Walser EM. Appropriate timing of cholecystectomy in patients who present with moderate to severe gallstone-associated acute pancreatitis with peripancreatic fluid collections. Ann Surg 2004; 239: 741 - 749; discussion 749-751

[173] Uhl W, Muller CA, Krahenbuhl L et al. Acute gallstone pancreatitis: timing of laparoscopic cholecystectomy in mild and severe disease. Surg Endosc 1999; 13: 1070-1076

[174] Hwang SS, Li BH, Haigh PI. Gallstone pancreatitis without cholecystectomy. JAMA Surg 2013; 148: 867 -872

[175] Uomo G, Manes G, Laccetti M et al. Endoscopic sphincterotomy and recurrence of acute pancreatitis in gallstone patients considered unfit for surgery. Pancreas 1997; 14: 28 - 31

[176] ElGeidie AA, ElEbidy GK, Naeem YM. Preoperative versus intraoperative endoscopic sphincterotomy for management of common bile duct stones. Surg Endosc 2011; 25: 1230 - 1237

[177] Noel R, Enochsson L, Swahn F et al. A 10-year study of rendezvous intraoperative endoscopic retrograde cholangiography during cholecystectomy and the risk of post-ERCP pancreatitis. Surg Endosc 2013; 27: $2498-2503$

[178] Tzovaras G, Baloyiannis I, Zachari E et al. Laparoendoscopic rendezvous versus preoperative ERCP and laparoscopic cholecystectomy for the management of cholecysto-choledocholithiasis: interim analysis of a controlled randomized trial. Ann Surg 2012; 255: 435 439

[179] Sahoo MR, Kumar AT, Patnaik A. Randomised study on single stage laparo-endoscopic rendezvous (intra-operative ERCP) procedure versus two stage approach (Pre-operative ERCP followed by laparoscopic cholecystectomy) for the management of cholelithiasis with choledocholithiasis. J Minim Access Surg 2014; 10: 139-143

[180] Morino M, Baracchi F, Miglietta C et al. Preoperative endoscopic sphincterotomy versus laparoendoscopic rendezvous in patients with gallbladder and bile duct stones. Ann Surg 2006; 244: 889 893 ; discussion 893-886

[181] Rabago LR, Vicente C, Soler F et al. Two-stage treatment with preoperative endoscopic retrograde cholangiopancreatography (ERCP) compared with single-stage treatment with intraoperative ERCP for patients with symptomatic cholelithiasis with possible choledocholithiasis. Endoscopy 2006; 38: 779 - 786

[182] Lella F, Bagnolo F, Rebuffat C et al. Use of the laparoscopic-endoscopic approach, the so-called "rendezvous" technique, in cholecystocholedocholithiasis: a valid method in cases with patientrelated risk factors for post-ERCP pancreatitis. Surg Endosc 2006; 20: $419-423$
[183] Borzellino G, Rodella L, Saladino E et al. Treatment for retained [corrected] common bile duct stones during laparoscopic cholecystectomy: the rendezvous technique. Arch Surg 2010; 145: 1145 1149

[184] Miscusi G, Gasparrini M, Petruzziello L et al. [Endolaparoscopic "Rendez-vous" in the treatment of cholecysto-choledochal calculosis]. G Chir 1997; 18: 655-657

[185] Cavina E, Franceschi M, Sidoti F et al. Laparo-endoscopic "rendezvous": a new technique in the choledocholithiasis treatment. Hepatogastroenterology 1998; 45: $1430-1435$

[186] Filauro M, Comes P, De Conca V et al. Combined laparoendoscopic approach for biliary lithiasis treatment. Hepatogastroenterology 2000; 47: $922-926$

[187] Tatulli F, Cuttitta A. Laparoendoscopic approach to treatment of common bile duct stones. J Laparoendosc Adv Surg Tech A 2000; 10 $315-317$

[188] Iodice G, Giardiello C, Francica G et al. Single-step treatment of gallbladder and bile duct stones: a combined endoscopic-laparoscopic technique. Gastrointest Endosc 2001; 53: 336 - 338

[189] Tricarico A, Cione G, Sozio M et al. Endolaparoscopic rendezvous treatment: a satisfying therapeutic choice for cholecystocholedocolithiasis. Surg Endosc 2002; 16: 585 - 588

[190] Enochsson L, Lindberg B, Swahn F et al. Intraoperative endoscopic retrograde cholangiopancreatography (ERCP) to remove common bile duct stones during routine laparoscopic cholecystectomy does not prolong hospitalization: a 2-year experience. Surg Endosc 2004; 18: $367-371$

[191] Saccomani G, Durante V, Magnolia MR et al. Combined endoscopic treatment for cholelithiasis associated with choledocholithiasis. Surg Endosc 2005; 19: 910 - 914

[192] La Greca G, Barbagallo F, Di Blasi M et al. Rendezvous technique versus endoscopic retrograde cholangiopancreatography to treat bile duct stones reduces endoscopic time and pancreatic damage. J Laparoendosc Adv Surg Tech A 2007; 17: 167 -171

[193] Ghazal AH, Sorour MA, El-Riwini M et al. Single-step treatment of gal bladder and bile duct stones: a combined endoscopic-laparoscopic technique. Int J Surg 2009; 7: $338-346$

[194] Tzovaras G, Baloyiannis I, Kapsoritakis A et al. Laparoendoscopic rendezvous: an effective alternative to a failed preoperative ERCP in patients with cholecystocholedocholithiasis. Surg Endosc 2010; 24: $2603-2606$

[195] Swahn F, Regner S, Enochsson L et al. Endoscopic retrograde cholangiopancreatography with rendezvous cannulation reduces pancreatic injury. World J Gastroenterol 2013; 19: 6026-6034

[196] Tommasi C, Bencini L, Bernini M et al. Routine use of simultaneous laparoendoscopic approach in patients with confirmed gallbladder and bile duct stones: fit for laparoscopy fit for "rendezvous". World J Surg 2013; 37: 999-1005

[197] Di Mauro D, Faraci R, Mariani L et al. Rendezvous technique for cholecystocholedochal lithiasis in octogenarians: is it as effective as in younger patients, or should endoscopic sphincterotomy followed by laparoscopic cholecystectomy be preferred? J Laparoendosc Adv Surg Tech A 2014; 24: $13-21$

[198] Arezzo A, Vettoretto N, Famiglietti F et al. Laparoendoscopic rendezvous reduces perioperative morbidity and risk of pancreatitis. Surg Endosc 2013; 27: 1055 - 1060

[199] Wang B, Guo Z, Liu Z et al. Preoperative versus intraoperative endoscopic sphincterotomy in patients with gallbladder and suspected common bile duct stones: system review and meta-analysis. Surg Endosc 2013; 27: 2454-2465

[200] Gurusamy K, Sahay S], Burroughs AK et al. Systematic review and meta-analysis of intraoperative versus preoperative endoscopic sphincterotomy in patients with gallbladder and suspected common bile duct stones. Br J Surg 2011; 98: 908 -916 
[201] Huang L, Yu QS, Zhang Q et al. The rendezvous technique for common bile duct stones: a meta-analysis. Surg Laparosc Endosc Percu$\tan$ Tech 2015; 25: $462-470$

[202] Tan C, Ocampo O, Ong R et al. Comparison of one stage laparoscopic cholecystectomy combined with intra-operative endoscopic sphincterotomy versus two-stage pre-operative endoscopic sphincterotomy followed by laparoscopic cholecystectomy for the management of pre-operatively diagnosed patients with common bile duct stones: a meta-analysis. Surg Endosc 2018; 32: 770 - 778

[203] Swahn F, Nilsson M, Arnelo U et al. Rendezvous cannulation technique reduces post-ERCP pancreatitis: a prospective nationwide study of 12,718 ERCP procedures. Am J Gastroenterol 2013; 108: $552-559$

[204] Hong DF, Xin Y, Chen DW. Comparison of laparoscopic cholecystectomy combined with intraoperative endoscopic sphincterotomy and laparoscopic exploration of the common bile duct for cholecystocholedocholithiasis. Surg Endosc 2006; 20: 424-427

[205] Dasari BV, Tan C], Gurusamy KS et al. Surgical versus endoscopic treatment of bile duct stones. Cochrane Database Syst Rev 2013 CD003327

[206] Kenny R, Richardson J, McGlone ER et al. Laparoscopic common bile duct exploration versus pre or post-operative ERCP for common bile duct stones in patients undergoing cholecystectomy: is there any difference? Int J Surg 2014; 12: 989-993

[207] Alexakis N, Connor S. Meta-analysis of one- vs. two-stage laparoscopic/endoscopic management of common bile duct stones. HPB (Oxford) 2012; 14: 254-259

[208] Rhodes M, Sussman L, Cohen L et al. Randomised trial of laparoscopic exploration of common bile duct versus postoperative endoscopic retrograde cholangiography for common bile duct stones. Lancet 1998; 351: 159-161

[209] Cuschieri A, Lezoche E, Morino M et al. E.A.E.S. multicenter prospective randomized trial comparing two-stage vs single-stage management of patients with gallstone disease and ductal calculi. Surg Endosc 1999; 13: 952 - 957

[210] Sgourakis G, Karaliotas K. Laparoscopic common bile duct exploration and cholecystectomy versus endoscopic stone extraction and laparoscopic cholecystectomy for choledocholithiasis. A prospective randomized study. Minerva Chir 2002; 57: 467-474

[211] Nathanson LK, O'Rourke NA, Martin IJ et al. Postoperative ERCP versus laparoscopic choledochotomy for clearance of selected bile duct calculi: a randomized trial. Ann Surg 2005; 242: 188- 192

[212] Noble H, Tranter S, Chesworth T et al. A randomized, clinical trial to compare endoscopic sphincterotomy and subsequent laparoscopic cholecystectomy with primary laparoscopic bile duct exploration during cholecystectomy in higher risk patients with choledocholithiasis. J Laparoendosc Adv Surg Tech A 2009; 19: 713-720

[213] Rogers S], Cello JP, Horn JK et al. Prospective randomized trial of LC $+\mathrm{LCBDE}$ vs ERCP/S+LC for common bile duct stone disease. Arch Surg 2010; 145: $28-33$

[214] Bansal VK, Misra MC, Rajan K et al. Single-stage laparoscopic common bile duct exploration and cholecystectomy versus two-stage endoscopic stone extraction followed by laparoscopic cholecystectomy for patients with concomitant gallbladder stones and common bile duct stones: a randomized controlled trial. Surg Endosc 2014; 28: $875-885$

[215] Bansal VK, Misra MC, Garg P et al. A prospective randomized trial comparing two-stage versus single-stage management of patients with gallstone disease and common bile duct stones. Surg Endosc 2010; 24: 1986 - 1989

[216] Koc B, Karahan S, Adas G et al. Comparison of laparoscopic common bile duct exploration and endoscopic retrograde cholangiopancreatography plus laparoscopic cholecystectomy for choledocholithiasis: a prospective randomized study. Am J Surg 2013; 206: 457 - 463
[217] Ding G, Cai W, Qin M. Single-stage vs. two-stage management for concomitant gallstones and common bile duct stones: a prospective randomized trial with long-term follow-up. J Gastrointest Surg 2014; 18: $947-951$

[218] Singh AN, Kilambi R. Single-stage laparoscopic common bile duct exploration and cholecystectomy versus two-stage endoscopic stone extraction followed by laparoscopic cholecystectomy for patients with gallbladder stones with common bile duct stones: systematic review and meta-analysis of randomized trials with trial sequential analysis. Surg Endosc 2018; 32: 3763 - 3776

[219] Poulose BK, Arbogast PG, Holzman MD. National analysis of in-hospital resource utilization in choledocholithiasis management using propensity scores. Surg Endosc 2006; 20: 186 - 190

[220] Arvanitakis M, Dumonceau JM, Albert J et al. Endoscopic management of acute necrotizing pancreatitis: European Society of Gastrointestinal Endoscopy (ESGE) evidence-based multidisciplinary guidelines. Endoscopy 2018; 50: 524-546

[221] Kiriyama S, Takada T, Strasberg SM et al. TG13 guidelines for diagnosis and severity grading of acute cholangitis (with videos). J Hepatobiliary Pancreat Sci 2013; 20: $24-34$

[222] Kiriyama S, Kozaka K, Takada T et al. Tokyo Guidelines 2018: diagnostic criteria and severity grading of acute cholangitis (with videos). J Hepatobiliary Pancreat Sci 2018; 25: 17 - 30

[223] Karvellas C], Abraldes JG, Zepeda-Gomez S et al. The impact of delayed biliary decompression and anti-microbial therapy in $260 \mathrm{pa}-$ tients with cholangitis-associated septic shock. Aliment Pharmacol Ther 2016; 44: 755 - 766

[224] Schwed AC, Boggs MM, Pham XD et al. Association of admission laboratory values and the timing of endoscopic retrograde cholangiopancreatography with clinical outcomes in acute cholangitis. JAMA Surg 2016; 151: 1039-1045

[225] Park CS, Jeong HS, Kim KB et al. Urgent ERCP for acute cholangitis reduces mortality and hospital stay in elderly and very elderly patients. Hepatobiliary Pancreat Dis Int 2016; 15: 619-625

[226] Lee F, Ohanian E, Rheem J et al. Delayed endoscopic retrograde cholangiopancreatography is associated with persistent organ failure in hospitalised patients with acute cholangitis. Aliment Pharmacol Ther 2015; 42: $212-220$

[227] Navaneethan U, Gutierrez NG, Jegadeesan R et al. Factors predicting adverse short-term outcomes in patients with acute cholangitis undergoing ERCP: A single center experience. World J Gastrointest Endosc 2014; 6: 74-81

[228] Navaneethan U, Gutierrez NG, Jegadeesan R et al. Delay in performing ERCP and adverse events increase the 30-day readmission risk in patients with acute cholangitis. Gastrointest Endosc 2013; 78: 81 90

[229] Jang SE, Park SW, Lee BS et al. Management for CBD stone-related mild to moderate acute cholangitis: urgent versus elective ERCP. Dig Dis Sci 2013; 58: $2082-2087$

[230] Khashab MA, Tariq A, Tariq U et al. Delayed and unsuccessful endoscopic retrograde cholangiopancreatography are associated with worse outcomes in patients with acute cholangitis. Clin Gastroenterol Hepatol 2012; 10: 1157-1161

[231] Mok SR, Mannino CL, Malin J et al. Does the urgency of endoscopic retrograde cholangiopancreatography (ERCP)/percutaneous biliary drainage (PBD) impact mortality and disease related complications in ascending cholangitis? (DEIM-I study) J Interv Gastroenterol 2012; 2: $161-167$

[232] Chak A, Cooper GS, Lloyd LE et al. Effectiveness of ERCP in cholangitis: a community-based study. Gastrointest Endosc 2000; 52: 484 489

[233] Navaneethan U, Njei B, Hasan MK et al. Timing of ERCP and outcomes of patients with acute cholangitis and choledocholithiasis: a 
nationwide population based study. Gastrointest Endosc 2015; 81: $\mathrm{AB} 354$

[234] Patel H, Gaduputi V, Chelimilla H et al. Acute cholangitis: does the timing of ERCP alter outcomes? JOP 2016; 17: 504 - 509

[235] Jamidar PA, Beck GJ, Hoffman BJ et al. Endoscopic retrograde cholangiopancreatography in pregnancy. Am J Gastroenterol 1995; 90: $1263-1267$

[236] Kahaleh M, Hartwell GD, Arseneau KO et al. Safety and efficacy of ERCP in pregnancy. Gastrointest Endosc 2004; 60: 287-292

[237] Lee J], Lee SK, Kim SH et al. Efficacy and safety of pancreatobiliary endoscopic procedures during pregnancy. Gut Liver 2015; 9: 672 678

[238] Shelton J, Linder JD, Rivera-Alsina ME et al. Commitment, confirmation, and clearance: new techniques for nonradiation ERCP during pregnancy (with videos). Gastrointest Endosc 2008; 67: 364 - 368

[239] Tang S], Mayo MJ, Rodriguez-Frias E et al. Safety and utility of ERCP during pregnancy. Gastrointest Endosc 2009; 69: 453-461

[240] Tham TC, Vandervoort ], Wong RC et al. Safety of ERCP during pregnancy. Am J Gastroenterol 2003; 98: 308-311
[241] Jorgensen JE, Rubenstein JH, Goodsitt MM et al. Radiation doses to ERCP patients are significantly lower with experienced endoscopists. Gastrointest Endosc 2010; 72: 58-65

[242] Uradomo LT, Lustberg ME, Darwin PE. Effect of physician training on fluoroscopy time during ERCP. Dig Dis Sci 2006; 51: $909-914$

[243] Dumonceau JM, Garcia-Fernandez FJ, Verdun FR et al. Radiation protection in digestive endoscopy: European Society of Digestive Endoscopy (ESGE) guideline. Endoscopy 2012; 44: 408 - 421

[244] Freeman ML, Nelson DB, Sherman S et al. Complications of endoscopic biliary sphincterotomy. NEJM 1996; 335: 909-918

[245] ASGE Standard of Practice Committee, Shergill AK, Ben-Menachem T et al. Guidelines for endoscopy in pregnant and lactating women. Gastrointest Endosc 2012; 76: 18-24

[246] Valentin ]. Effects of in utero irradiation. Ann ICRP 2000; 30: 9-12

[247] Wu W, Faigel DO, Sun G et al. Non-radiation endoscopic retrograde cholangiopancreatography in the management of choledocholithiasis during pregnancy. Dig Endosc 2014; 26: 691 - 700 